\title{
Benthic-pelagic coupling and the seasonal silica cycle in the Bay of Brest (France): new insights from a coupled physical-biological model
}

\author{
G. G. Laruelle ${ }^{1, *}$, P. Regnier ${ }^{1,2}$, O. Ragueneau ${ }^{3}$, M. Kempa ${ }^{3}$, B. Moriceau ${ }^{3}$, \\ S. Ni Longphuirt ${ }^{3}$, A. Leynaert ${ }^{3}$, G. Thouzeau ${ }^{3}$, L. Chauvaud ${ }^{3}$ \\ ${ }^{1}$ Faculty of Geosciences, Department of Earth Sciences - Geochemistry, Utrecht University, PO Box 80021, 3508 TA Utrecht, \\ The Netherlands \\ ${ }^{2}$ Department of Earth and Environmental Sciences, Université Libre de Bruxelles, Brussels, Belgium \\ ${ }^{3}$ UMR CNRS 6539, Institut Universitaire Européen de la Mer, Place Copernic,Technopôle Brest-Iroise, 29280 Plouzané, France
}

\begin{abstract}
A fully transient, 2-dimensional physical and biological model has been developed to quantify the seasonal cycle of silica in the estuaries-coastal zone continuum of the Bay of Brest (France). The numerical model includes an explicit representation of the benthic-pelagic coupling, which is stimulated by the increasing density of an invasive megabenthic filter feeder, the slipper limpet Crepidula fornicata. The selected spatial resolution allows resolution of the heterogeneous density distribution of these organisms in the bay. Results show that the benthic nutrient dynamics are highly variable and strongly depend on the local conditions. This heterogeneity is not reflected in the pelagic phytoplankton population dynamics because transport and mixing homogenize the distribution of nutrients and biomass. A seasonally resolved silica budget over the entire bay and estuaries emphasizes the important contribution of the benthic recycling fluxes to the supply of dissolved silica (dSi) during the productive period ( $50 \%$ from 1 April to 1 September). In a prognostic scenario which forecasts the impact of removing the invasive benthic filter feeders, the dSi efflux is reduced by $63 \%$ and a pronounced harmful algal bloom of dinoflagellates develops in late summer.
\end{abstract}

KEY WORDS: Crepidula fornicata $\cdot$ Dissolved silica $\cdot$ Harmful algal bloom $\cdot$ Benthic-pelagic coupling · Nutrient cycles

\section{INTRODUCTION}

Like many other coastal areas worldwide (Cloern 2001), the Bay of Brest (NW France) is a macrotidal embayment which is subject to major anthropogenic pressure. In this ecosystem, nitrogen inputs from agricultural practices in the watersheds have doubled since the 1970s (Le Pape et al. 1996). At the same time, the gastropod Crepidula fornicata invaded the bay and became the main benthic suspension feeder within the megafauna during the early 1990s. (Chauvaud et al. 2000). In 2000, it covered approximately half of the entire benthic surface area of the bay (Chauvaud 1998).

Despite the marked increase in dissolved inorganic nitrogen (DIN) inputs, the Bay of Brest has not experi- enced any major eutrophication events so far. Such dynamics have been attributed to the fact that most of the nutrient delivery occurs before the start of the productive season. In addition, it has been argued that the estuarine processes occurring upstream and the macrotidal dynamics in the bay itself were not providing favorable conditions for the onset of eutrophication (Le Pape et al. 1996). More surprisingly, however, no significant perturbation of the pelagic food-web structure related to the long-term decline in the dissolved silica (dSi):DIN ratio which accompanied the increase in nitrate inputs has yet been observed (Ragueneau 1994). In many ecosystems, such a decline has induced changes in phytoplankton dynamics - an increase in non-siliceous phytoplankton species at the expense of 
diatoms - with important implications for the pelagic and benthic food webs (Smayda 1990, Conley et al. 1993, Turner et al. 1998). However, as recently reviewed by Ragueneau et al. (2006a), such a shift in phytoplankton abundances due to modifications in nutrient ratios does not always occur. In particular, it has been advocated that the intensity of dSi recycling within a specific ecosystem plays an essential role in controlling the characteristics and succession of phytoplankton species. The recycling intensity modifies the properties of the various diatom species (Roberts et al. 2003), especially their degree of silicification (Rousseau et al. 2002), and ultimately favor the switch from diatom to non-diatom species when the dSi stress becomes too strong (Officer \& Ryther 1980).

Until very recently, diatoms have dominated the phytoplankton biomass throughout the productive period in the Bay of Brest (Del Amo et al. 1997b, Beucher et al. 2004), despite indirect (Ragueneau et al. 1994) and direct (Del Amo et al. 1997a, Ragueneau et al. 2002) evidence of a dSi limitation during spring. On the one hand, physical factors have been proposed (Ragueneau et al. 1996) to explain the limited occurrence of dinoflagellates, which generally prefer stratified water bodies (Margalef 1978). On the other hand, $\mathrm{dSi}$ recycling is significant in this ecosystem, both in the water column (Beucher et al. 2004) and in the sediments (Ragueneau et al. 1994, Martin et al. 2007), and therefore could explain the high resistance of the diatoms towards the decrease in the dSi:DIN ratio. Del Amo et al. (1997a) have suggested the existence of a coastal silicate pump similar to that of the oceanic silicate pump proposed by Dugdale et al. (1995), which extracts dSi from the surface waters, but instead of transferring it to the deep layers of the open ocean, it would here be directly transported and temporarily stored in the sediments. The subsequent benthic recycling flux of dSi during late spring and summer could then explain the maintenance of diatoms throughout the entire productive period. Since it has been suggested that the invasion of Crepidula fornicata significantly increased the efficiency of the silicate pump in the Bay of Brest (Chauvaud et al. 2000), the 2 major anthropogenic perturbations (nutrient load increase and invasive species) strongly interact in this ecosystem. The efficiency of the silicate pump is improved by the filtering and biodeposition activities of the benthic filter feeder, leading to a significant storage of biogenic silica $\left(\mathrm{bSiO}_{2}\right)$ in the sediments followed by dissolution later in the season when temperature increases. If true, such a hypothesis implies that the proliferation of the benthic filter feeder may have aided in the prevention, at least for some time, of the expected switch in phytoplankton dominance. From an integrated coastal zone management (ICZM) perspective, the possible positive effect of the invasive species, that is, its ability to prevent the development of non-diatom, possibly harmful, algal blooms, should thus be balanced with its negative impact on other native benthic species in the bay (e.g. the great scallop Pecten maximus).

Previous experimental studies have already investigated the direct impact of the presence of Crepidula fornicata on the magnitude of benthic recycling fluxes of dSi (Ragueneau et al. 2002, 2006b). In addition, seasonal and annual budgets of Si have been proposed (Ragueneau et al. 2005) and the importance of the benthic filter feeders in the Si seasonal cycle has clearly been established. Yet the feedback of this biologically driven silicate pump on the phytoplankton dynamics in the bay and, more specifically, its ability to maintain the diatom dominance despite the observed widespread dSi limitation are important research questions that remain essentially unanswered. These questions are, however, essential if one aims to forecast the potential effect of benthic filter feeder eradication on both the eutrophication and food-web structure in the bay. Such an engineered intervention has been planned since the early 2000s and, therefore, prognostic simulations are particularly timely to help design the best sustainable management strategy for the Bay of Brest.

In the present study, a 2-dimensional, depth-averaged, hydrodynamic and reactive-transport model has been developed for the estuaries and the Bay of Brest. The ecological and biogeochemical reaction network includes the dominant processes of the $\mathrm{Si}, \mathrm{C}$ and $\mathrm{N}$ cycles in the water column and surficial layers of the sediments. In particular, the model explicitly accounts for the feeding and biodeposition activities of Crepidula fornicata at the sediment-water interface. Model results are not only compared with measurements of standing stocks of nutrients and chlorophyll a (chl a), but also with in situ flux and rate measurements (e.g. silica production, benthic fluxes, etc.). Mesocosm experiments (Fouillaron et al. 2007) have shown that observations on process rates and material fluxes are essential to understand the biogeochemical dynamics in the bay. The model advances our understanding of the Si dynamics in the bay and enables us to establish temporally and spatially resolved budgets of silica and conduct prognostic simulation addressing the ecological consequences of partly eradicating the benthic filter feeder from the sea bed.

\section{MODEL SET-UP}

Hydrodynamics and transport. Support: A 2-dimensional, vertically integrated numerical model (MIKE 21, www.dhisoftware.com/mike21) was used to com- 
pute the flow field in the Aulne and Elorn estuaries, the Bay of Brest and the inner part of the Iroise Sea (Fig. 1). The model extends upstream in the Aulne and Elorn up to the limit of tidal influence where unidirectional flow is maintained at all times. The marine boundary in the Iroise Sea is set to longitude $4^{\circ} 36^{\prime} \mathrm{W}$. The land boundaries and bathymetry were obtained from the Service hydrologique et océanographique de la marine (SHOM) digital charts. Spatial resolutions of the bathymetric surveys in the Iroise Sea, the Bay of Brest and the Aulne and Elorn estuaries were on the order of 500, 100 and $200 \mathrm{~m}$, respectively. The hydrodynamic model was run over the entire domain with a spatial resolution of $150 \times 150 \mathrm{~m}$. Time series of water elevation were then extracted along a transect through the narrow strait between the bay and the Iroise Sea (Goulet, Fig. 1) and used to force a smaller scale, coupled physical-biological model which was run over the entire year of 2001.

Hydrodynamics: The hydrodynamic model was based on the vertically integrated volume (Eq. 1) and momentum conservation equations (Eqs. 2 \& 3) for barotropic flow:

$$
\begin{gathered}
\frac{\partial \zeta}{\partial t}+\frac{\partial p}{\partial x}+\frac{\partial q}{\partial y}=0 \\
\frac{\partial p}{\partial t}+\frac{\partial}{\partial x}\left(\frac{p^{2}}{h}\right)+\frac{\partial}{\partial y}\left(\frac{p q}{h}\right)+g h \frac{\partial \zeta}{\partial x}+\frac{g p \sqrt{p^{2}+q^{2}}}{M^{2} h^{1 / 3} h^{2}} \\
-\left[E_{x} \frac{\partial^{2} p}{\partial x^{2}}+E_{y} \frac{\partial^{2} p}{\partial y^{2}}\right]-\Omega q-f(V) V_{x}=0 \\
\frac{\partial q}{\partial t}+\frac{\partial}{\partial y}\left(\frac{q^{2}}{h}\right)+\frac{\partial}{\partial x}\left(\frac{p q}{h}\right)+g h \frac{\partial \zeta}{\partial y}+\frac{g q \sqrt{p^{2}+q^{2}}}{M^{2} h^{1 / 3} h^{2}} \\
-\left[E_{x} \frac{\partial^{2} q}{\partial y^{2}}+E_{y} \frac{\partial^{2} q}{\partial x^{2}}\right]+\Omega p-f(V) V_{y}=0
\end{gathered}
$$

This set of coupled non-linear partial differential equations (PDEs) resolves the spatial $(x, y)$ and temporal $(t)$ dynamics of surface water elevation, $\zeta(\mathrm{m})$, and scalar components of the momentum fluxes, $p$ and $q$ $\left(\mathrm{m}^{2} \mathrm{~s}^{-1}\right)$. The flux densities $p$ and $q$ are defined per unit length along the $y$ and $x$ coordinates, respectively. In Eqs. (2) \& (3), $h$ is the water depth (m), $g$ is the Earth's gravitation constant $\left(\mathrm{m} \mathrm{s}^{-2}\right), \Omega$ is the Coriolis parameter $\left(\mathrm{s}^{-1}\right)$ and $M$ is the Manning-Strickler coefficient $\left(\mathrm{m}^{1 / 3}\right.$ $\mathrm{s}^{-1}$ ), which is used to constrain the bed friction. The effect of wind stress (last term on the left side of Eqs. 2 $\& 3)$ is also taken into account in the momentum balance, using daily data of wind speed $(V)$ and direction obtained $10 \mathrm{~m}$ above the surface at the Lanvéoc Poulmic meteorological station $\left(48^{\circ} 16^{\prime} 57.11^{\prime} \mathrm{N}\right.$, $004^{\circ}$ $26^{\prime} 37.29^{\prime}$ W, Fig. 1). The wind friction factor $f(V)$ was calculated according to Smith \& Bank (1992). The system of PDEs was solved by finite differences with appropriate initial and boundary conditions using a non-iterative alternating direction implicit algorithm (Abbott 1979).

The Manning-Strickler and eddy viscosity coefficients, $M$ and $E_{X, Y}\left(\mathrm{~m}^{2} \mathrm{~s}^{-1}\right)$, respectively, are model calibration parameters that must be specified. Eddy viscosity coefficients are proportional to the local current velocities and calculated with the Smagorinsky formula (Smagorinsky 1963) using a proportionality constant of 0.5 . For bed friction, a Manning-Strickler value of 60 has been used over the entire domain.

Transport: The mass conservation equation for scalar components (salt and biogeochemical variables) is based on the vertically integrated advectiondispersion equation:

$$
\begin{array}{r}
\frac{\partial}{\partial t}(h c)+\frac{\partial}{\partial x}(u h c)+\frac{\partial}{\partial y}(v h c)-\frac{\partial}{\partial x}\left(h \cdot D_{x} \frac{\partial c}{\partial x}\right) \\
-\frac{\partial}{\partial y}\left(h \cdot D_{y} \frac{\partial c}{\partial y}\right)+\Sigma R+S=0
\end{array}
$$

where $c$ is the species concentration $\left(\mathrm{mol} \mathrm{m}^{-3}\right), u=p / h$ and $v=q / h$ are the horizontal components of the velocity vector $\left(\mathrm{m} \mathrm{s}^{-1}\right)$, and $D_{x}$ and $D_{y}$ are the eddy dispersion coefficients $\left(\mathrm{m}^{2} \mathrm{~s}^{-1}\right)$. The hydrodynamic model provides the horizontal velocity components $u$ and $v$ as well as the water depth, $h$. In Eq. (4), $\Sigma R$ is the rate of production or consumption of the species by the sum of biogeochemical processes, defined per unit surface area $\left(\mathrm{mol} \mathrm{m}^{-2} \mathrm{~s}^{-1}\right)$, and $S\left(\mathrm{~mol} \mathrm{~m} \mathrm{~m}^{-2} \mathrm{~s}^{-1}\right)$ is a source/sink term defining the local exchange of the species between the water column and the sediment.

The equation was solved for the spatial and temporal evolution of the concentration field using appropriate initial and boundary conditions (see below). Numerical integration of Eq. (4) was performed using the thirdorder, explicit finite difference scheme QUICKEST (Ekebjærg \& Justesen 1991). The dispersion coefficients $D_{X}$ and $D_{Y}$ in Eq. (4) are model parameters that were set proportional to the local current velocities. The proportionality constant was adjusted until agreement with observed salinity profiles was achieved. Both the hydrodynamic and salt transport models were run with a time step of $20 \mathrm{~s}$ that guarantees stability of the numerical schemes. The biogeochemical model used to calculate the $\Sigma R$ and $S$ terms was numerically decoupled from the transport algorithm using an operator-splitting approach. To decrease computational times, it was run with a larger time step of numerical integration of $360 \mathrm{~s}$.

Biogeochemistry. Reaction network and state variables: The biogeochemical model was based on a reaction network (RN) that describes the pelagic and benthic processes involved in the $\mathrm{Si}$ and associated $\mathrm{C}$ and N cycles (Fig. 2) The biogeochemical model was implemented within the ECOLab ${ }^{\complement}$ environmental modeling 
tool of DHI (e.g. Vanderborght et al. 2007, Arndt et al. 2007). All pelagic state variables are subject to fluid flow motion while the benthic variables are fixed on the bed and, thus, not explicitly transported. The benthic compartment consists of the top layer of the sediment where biological activity is most intense. The pelagic $\mathrm{RN}$ is a slightly modified version of the reaction set proposed by Le Pape et al. (1996). The formulation of benthic processes also follows these authors, except for the dynamics of benthic diatoms (microphytobenthos) and filter feeders, as well as an improved formulation of opal dissolution. Table 1 lists all state variables and their respective units.

Briefly, 2 phytoplankton groups (diatoms [Dia] and dinoflagellates [Dino]) are distinguished in the model (Fig. 2). Pelagic diatom growth consumes both $\mathrm{dSi}$ and DIN, dinoflagellates only requiring DIN. Both phytoplankton species are grazed by zooplankton (Zoo). The death of diatoms supports a pool of freshly dead diatoms (FDDia) which, in turn, are decomposed to detritic nitrogen (NDet) and detritic silica (SiDet) (Jean 1994). A simpler formulation is used for the Dino and Zoo, which assumes a direct transformation into NDet upon death of organisms. Zooplankton also excrete DIN. The detritic material (SiDet and NDet) is partially mineralized in the water column and leads to the production of dissolved nutrients (dSi and DIN).

Overall, the state variables involved in the benthic RN are similar to the ones implemented in the pelagic compartment. The model accounts for living and freshly dead benthic diatoms (BDia and BFDDia), detritic pools of Si and N (BSiDet and BNDet) and pore-water dissolved inorganic nutrients (BdSi and BDIN). Benthic filter feeders (Ben), which graze on pelagic (Dia, FDDia and Dino) and benthic (BDia and BFDDia) microalgae groups are also explicitly represented. The grazing on benthic diatoms implicitly assumes that resuspension may occur (Richard 2005, Guarini et al. 2008). BDia consume both the silica and nitrogen present in the pore water. Their death and subsequent decomposition follows the same dynamics as the corresponding pelagic variable. Ben mortality increases the BNDet pool, excre-
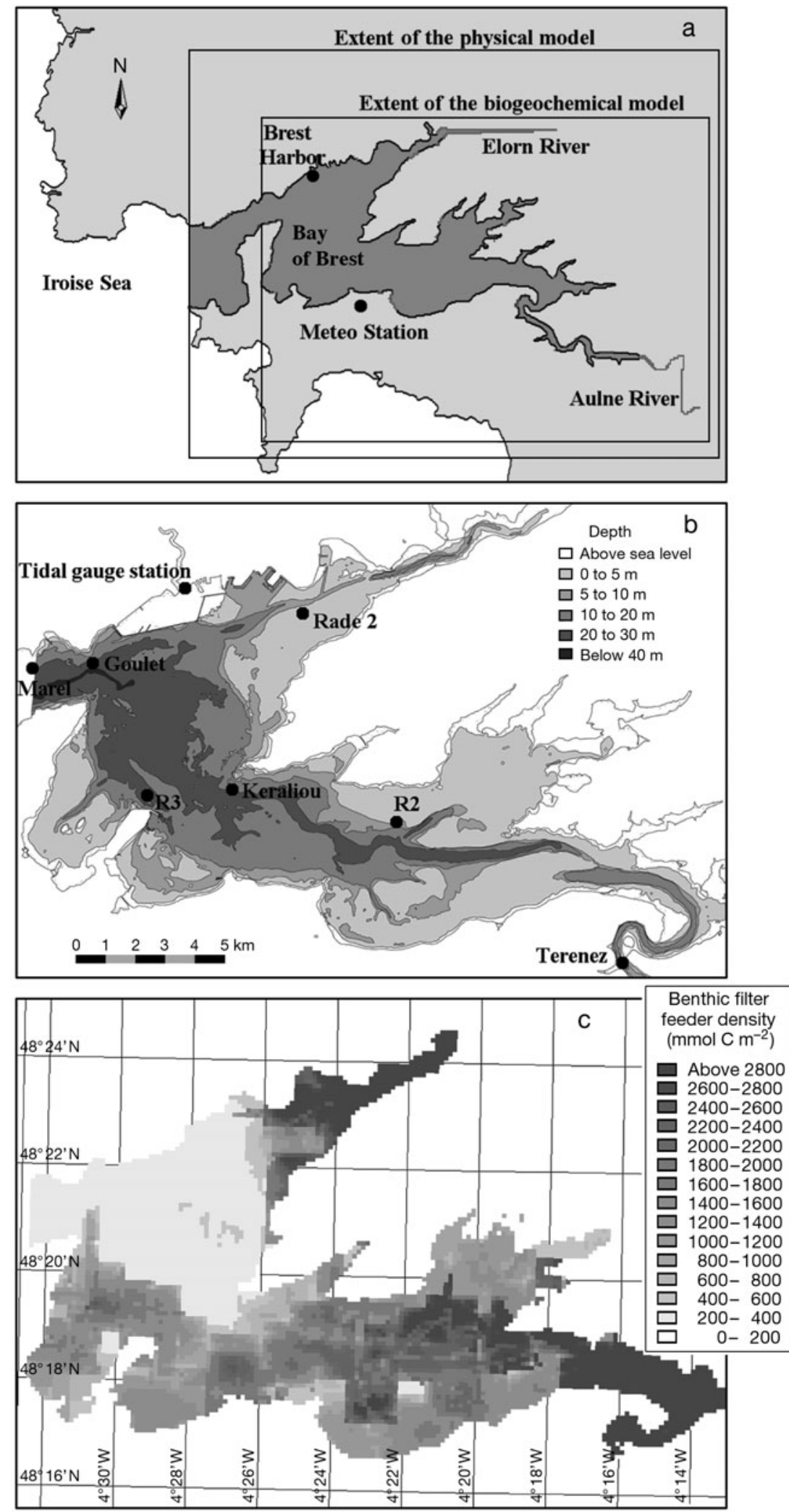

Fig. 1. (a) Geographical extent of the model, (b) bathymetric map of the Bay of Brest, France, and (c) spatial distribution of benthic filter feeder density. All locations and stations referred to in the text are shown in (a) and (b) 


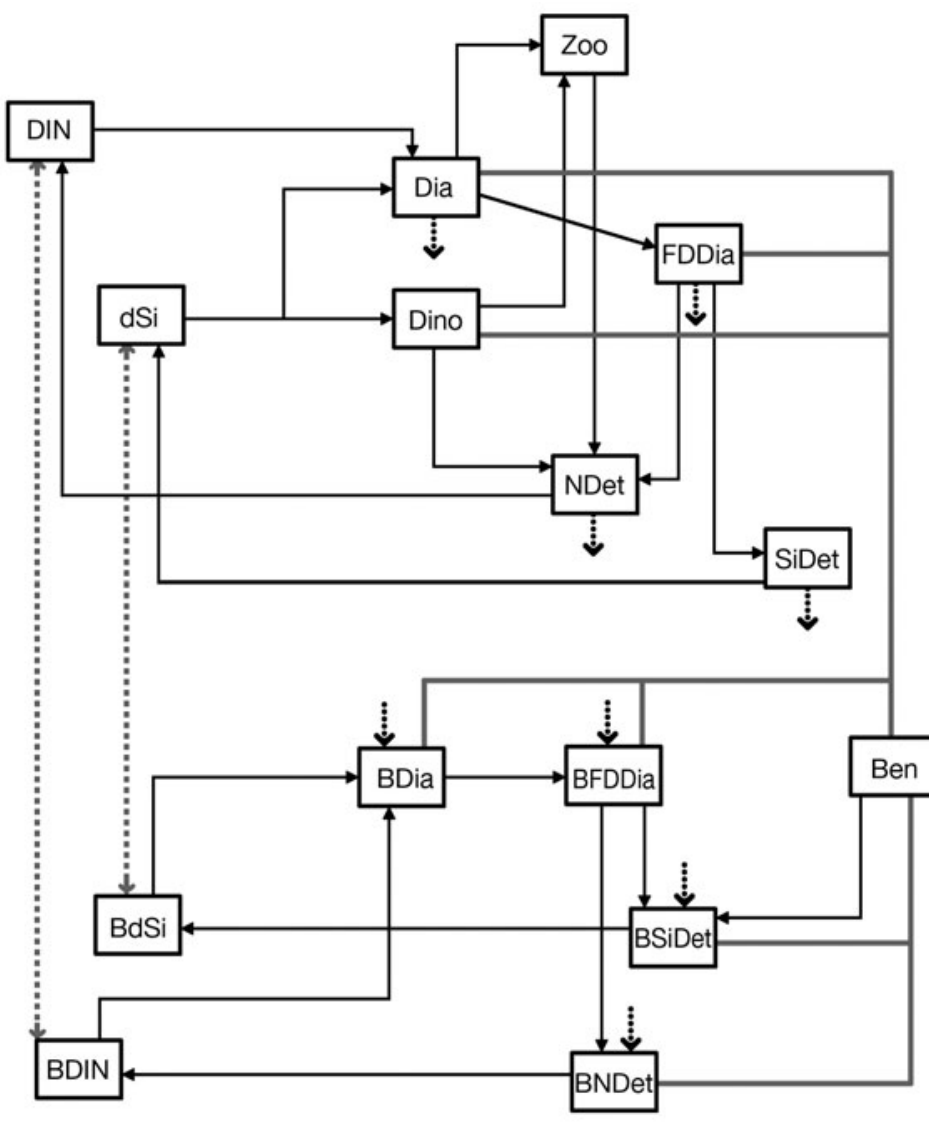

Fig. 2. Schematic representation of the biogeochemical model. Boxes and arrows represent the state variables and processes, respectively. Thin black lines characterize the pelagic and benthic processes. Benthic-pelagic coupling occurs through grazing by benthic filter feeders (thick grey lines), sedimentation (black dotted lines) and diffusion (grey dashed lines). See Table 1 for state variable abbreviations for both production (positive) and consumption (negative) processes affecting the chemical species considered.

All physiological and mineralization processes are temperature dependent. In addition, the growth of pelagic and benthic microalgae depends both on light and nutrient availability, whose respective limitations are combined using Liebig's law (Von Liebig 1840). A detailed description of the equations implemented in our RN, including all parameter values, is given in Appendix 1.

Boundary conditions: The Service d'Observation en Milieu Littoral (SOMLIT) database (www. domino.u-bordeaux.fr/somlit_national/pSiteBrest. php) and the buoy-mounted MAREL (www. ifremer.fr/sismer/UK/catal/base/edmed_an.htql? CBASE=MAREL2) automated acquisition system (Fig. 1) provide high frequency nutrient and total chl a data (sampling interval between 20 and $60 \mathrm{~min}$ ) at the Goulet site for the year 2001. At this location, the annual evolution of the relative proportions of diatoms and dinoflagellates is taken from Beucher et al. (2004). Following Le Pape (1996), zooplankton concentration was set to $10 \%$ of the total phytoplankton concentration.

Nutrient concentrations at the upstream limits of the model domain were specified using weekly measurements performed in the framework of the ECOFlux program (www.univ-brest.fr/IUEM/ observation/ecoflux/ecoflux.htm). In the present version of the model, it is assumed that no phytoplankton or zooplankton is introduced in the sys- tion releases BDIN and egestion produces both BSiDet and BNDet. Finally, the mineralization of BSiDet and BNDet releases inorganic nutrients (BdSi and BDIN).

Besides benthic grazing, the coupling between the pelagic and benthic compartments is realized through the sedimentation of Dia, FDDia, NDet and SiDet ( $S$ term negative in Eq. 4) which feeds the pools of BDia, BFDDia, BNDet and BSiDet, respectively. The diffusive fluxes of dissolved inorganic nutrients through the sediment-water interface, $J_{B}\left(\mathrm{~mol} \mathrm{~m}^{-2} \mathrm{~s}^{-1}\right)$, provide a source of DIN and dSi to the water column ( $S$ term positive in Eq. 4). This flux is positive out of the sediment and the mass balance for the benthic variables therefore reads:

$$
\frac{\partial\left(H_{\mathrm{sed}} C_{B}\right)}{\partial t}=v_{\mathrm{sed}} \cdot C-J_{B}+\Sigma R_{B}
$$

where $H_{\text {sed }}$ is the thickness of the benthic layer (m), $V_{\text {sed }}$ is the sedimentation rate $\left(\mathrm{m} \mathrm{s}^{-1}\right), C_{B}$ is the concentration of the benthic state variable $\left(\mathrm{mol} \mathrm{m}^{-3}\right)$ and $R_{B}$ is the net benthic flux $\left(\mathrm{mol} \mathrm{m} \mathrm{m}^{-2} \mathrm{~s}^{-1}\right)$, accounting
Table 1. State variables of the models with their units and abbreviations

\begin{tabular}{|c|c|c|}
\hline Abbrev. & Definition & Unit \\
\hline Dia & Diatoms & $\mu \mathrm{mol} \mathrm{C} \mathrm{l}^{-1}$ \\
\hline Dino & Dinoflagellates & $\mu \mathrm{mol} \mathrm{C} \mathrm{l^{-1 }}$ \\
\hline Zoo & Zooplankton & $\mu \mathrm{mol} \mathrm{C} \mathrm{l}^{-1}$ \\
\hline DIN & $\begin{array}{l}\text { Pelagic dissolved inorganic } \\
\text { nitrogen }\end{array}$ & $\mu \mathrm{mol} \mathrm{N} \mathrm{l^{-1 }}$ \\
\hline NDet & Pelagic detritic nitrogen & $\mu \mathrm{mol} \mathrm{N} \mathrm{l^{-1 }}$ \\
\hline $\mathrm{dSi}$ & Pelagic dissolved silica & $\mu \mathrm{mol} \mathrm{Si} 1^{-1}$ \\
\hline SiDet & Pelagic detritic silica & $\mu \mathrm{mol} \mathrm{Si} 1^{-1}$ \\
\hline FDDia & Freshly dead diatoms & umol C $\mathrm{l}^{-1}$ \\
\hline BDIN & $\begin{array}{l}\text { Dissolved inorganic nitrogen } \\
\text { in pore waters }\end{array}$ & $\mathrm{mmol} \mathrm{N} \mathrm{m}{ }^{-2}$ \\
\hline BNDet & Benthic detritic nitrogen & $\mathrm{mmol} \mathrm{N} \mathrm{m}^{-2}$ \\
\hline $\mathrm{BdSi}$ & $\begin{array}{l}\text { Dissolved inorganic silica in } \\
\text { pore waters }\end{array}$ & $\mathrm{mmol} \mathrm{Si} \mathrm{m}{ }^{-2}$ \\
\hline BSiDet & Benthic detritic silicon & mmol Si m${ }^{-2}$ \\
\hline BDia & Benthic diatoms & $\mathrm{mmol} \mathrm{C} \mathrm{m} \mathrm{m}^{-2}$ \\
\hline BFDDia & Benthic freshly dead diatoms & $\mathrm{mmol} \mathrm{C} \mathrm{m}{ }^{-2}$ \\
\hline Ben & Benthic filter feeders & $\mathrm{mmol} \mathrm{C} \mathrm{m} \mathrm{m}^{-2}$ \\
\hline
\end{tabular}



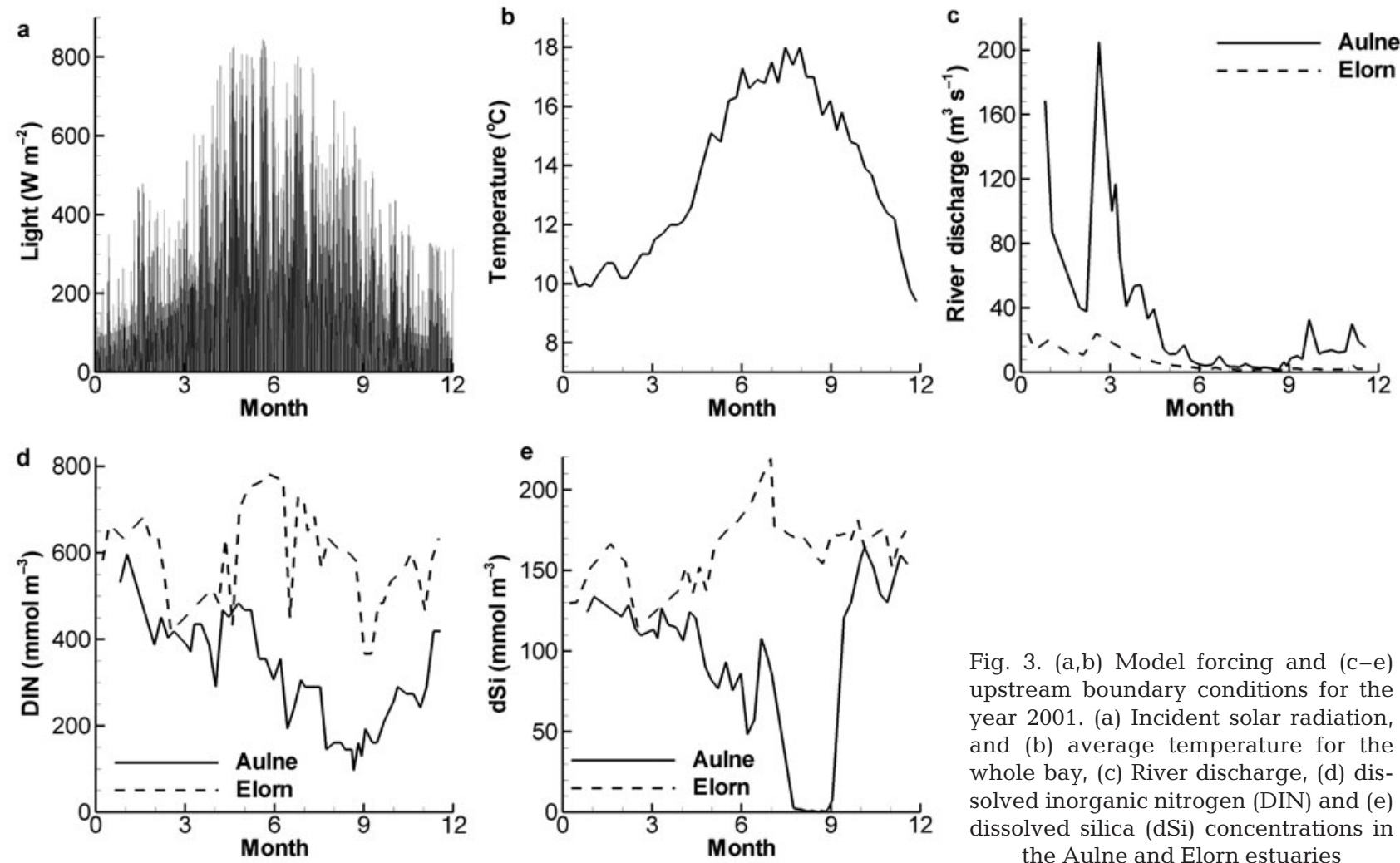

Fig. 3. $(a, b)$ Model forcing and $(c-e)$ upstream boundary conditions for the year 2001. (a) Incident solar radiation, and (b) average temperature for the whole bay, (c) River discharge, (d) dissolved inorganic nitrogen (DIN) and (e) dissolved silica (dSi) concentrations in the Aulne and Elorn estuaries

tem through the upper boundaries. There are only very few phytoplankton measurements at the upstream boundaries of the model and the few available data only provide information on total biomass without any further details on species distribution. Nutrient data are linearly interpolated between each sampling time interval to provide upstream concentrations at the frequency of the biogeochemical model resolution. Water discharge, dSi and DIN in the Aulne and Elorn estuaries during the year 2001 are shown in Fig. 3. The changes in forcing conditions (temperature and incident solar radiation) in the bay are also shown.

Initial conditions: The spin-up time for pelagic state variables in the model is on the order of 1 mo. To provide realistic initial conditions for the simulation, the model was launched on 1 December 2000, starting with spatially homogeneous concentrations. However, the benthic state variables exhibit much longer spinup times and, therefore, the model was run twice over the year 2001. Simulations reveal that in this case, the intra-annual seasonal variation is much larger than the inter-annual variability recorded from the difference between the ends of the first and second years. Note that for computational efficiency, the initial conditions are distributed homogeneously for all variables except the benthic filter feeders. The latter were estimated from recent maps of spatial distribution of Crepidula fornicata in the Bay of Brest (Guérin 2004), combined with an older estimate of the biomass of other benthic filter feeders (Chauvaud 1998, Jean \& Thouzeau 1995). The spatial distribution of C. fornicata was determined at 127 locations in the bay during the fall of 2000. The density at each model grid point in the bay was then determined by linear interpolation. Rivers were excluded from the survey and assumed here to be free of any benthic filter feeders. An average value of

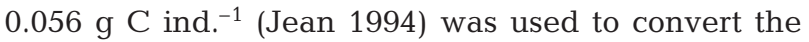
population density (ind. $\mathrm{m}^{-2}$ ) into carbon biomass. The contribution of all other benthic filter feeders (Jean \& Thouzeau 1995) was then added to C. fornicata to obtain the initial spatial distribution of total benthic filter feeder biomass. In the following, all model results correspond to the second year of simulation.

\section{RESULTS AND DISCUSSION}

\section{Hydrodynamics and transport}

Hydrodynamics

Model validation was performed on both water elevation and instantaneous tidal current velocities. Fig. 4 compares simulated and measured elevations recorded at the single tidal gauge station located in the bay (Fig. 1) for both spring and neap tide conditions. Over- 
Fig. 4. Time series of simulated (line) and measured (points) surface water elevation at Brest harbor for (a) spring and (b) neap tidal conditions
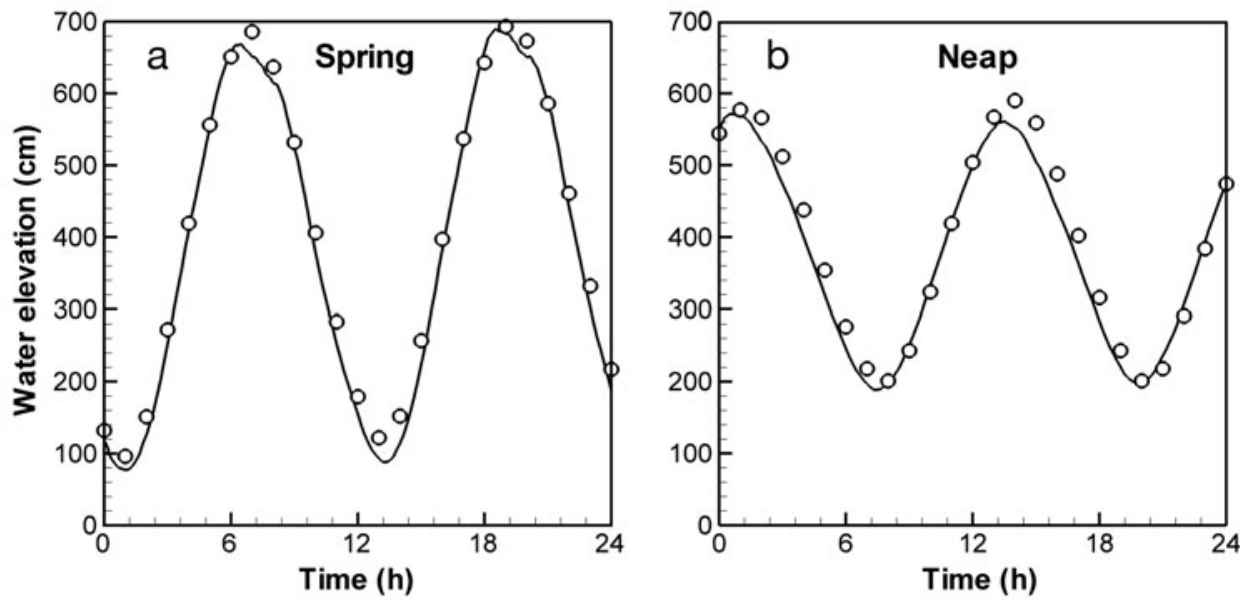

all agreement between modelled and measured tides is achieved with an error in tidal amplitude on the order of $5 \%$ and a deviation in phase never exceeding 15 min. Fig. 5 shows the simulated and measured components of the velocity vector at 4 locations in the bay (Fig. 1). One station (Terenez, Fig. 1b) is located near the mouth of the Aulne estuary, while the other stations are representative of the conditions encountered in the centre of the bay. Results reveal that both the magnitude and direction of the flow field are well captured by the model. The time lags among the various stations are also properly reproduced. In particular, the good fit at station Terenez, which is located farthest upstream, indicates that the tidal wave propagates accurately within the system.

The predicted tidal and residual circulations are in good agreement with previous hydrodynamic modelling studies (e.g. Le Pape 1996, Salomon \& Breton 1991). Model results show that the hydrodynamics is strongly dominated by the tidally induced circulation of semi-diurnal period. At each tide, the seawater volume that is exchanged with the Iroise Sea amounts roughly to $50 \%$ of the total volume of water in the bay (Chauvaud 1998). Fig. 6 shows the develop-

Fig. 5. Time series of simulated (lines) and measured (points) components of the velocity vectors $u$ (left) and $v$ (right) at 4 locations in the Bay of Brest, France. $u$ and $v$ represent the velocity of the current along the east-west and southnorth direction, respectively. Measured current velocity data are from the Service Hydrologique et Oceanographique de la Marine Francaise (SHOM)

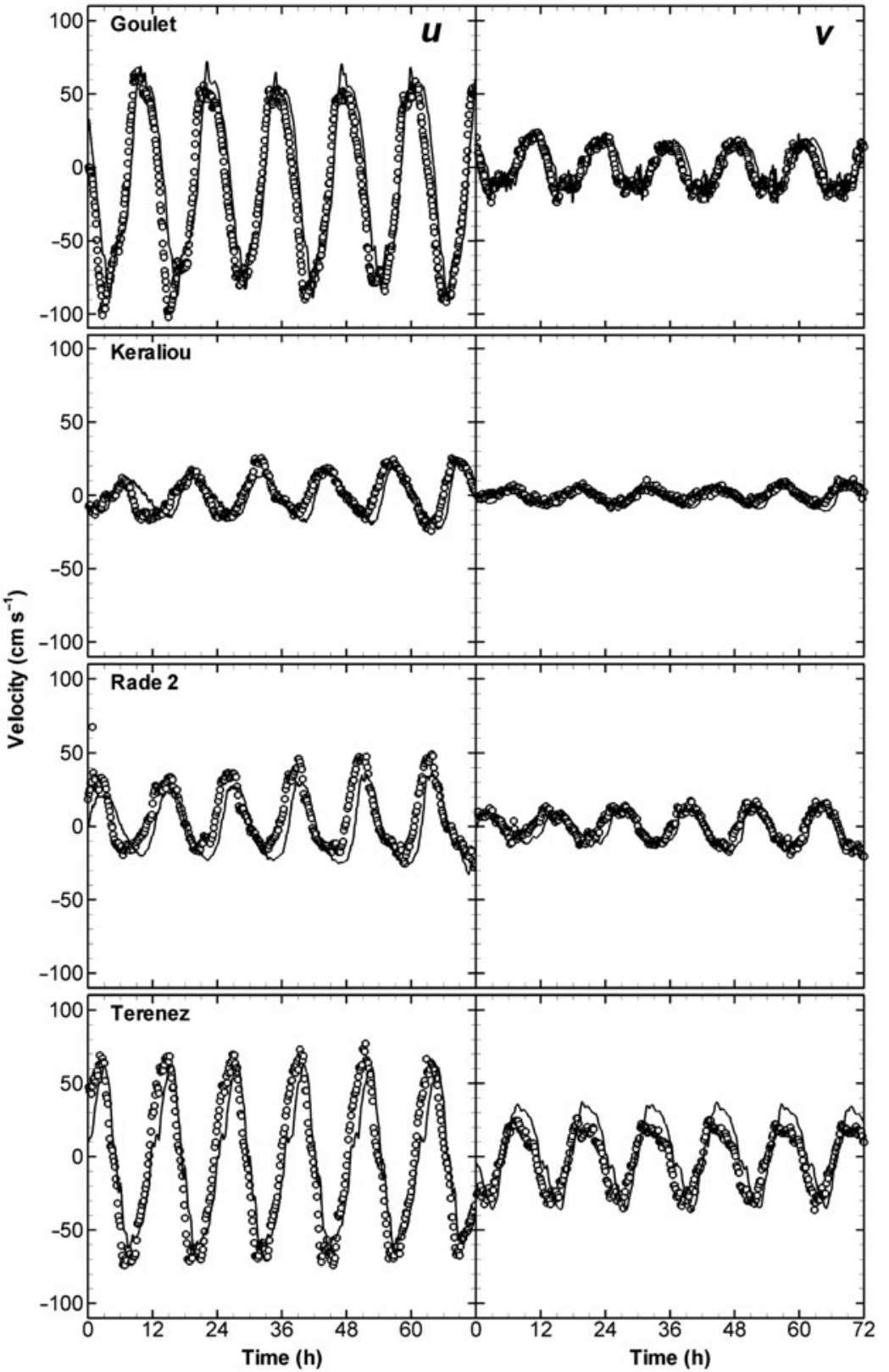




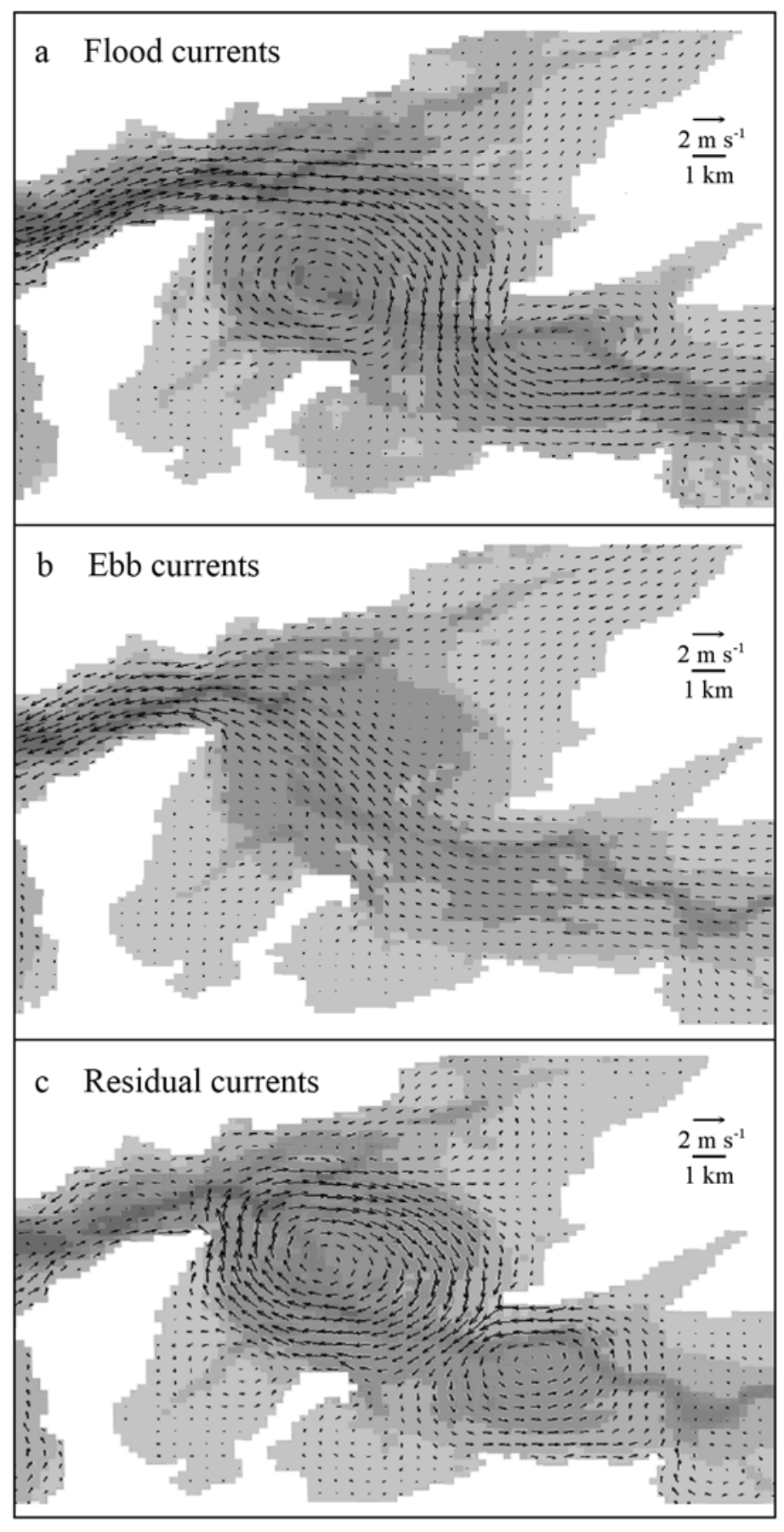

Fig. 6. Snapshot of the velocity vector field during (a) flood tide and (b) ebb tide. (c) Computed Eulerian residual circulation in the Bay of Brest and southern basins. During ebb, all large circulation features disappear and a uniform, retreating seaward flux of the water masses can be observed in the entire bay (Fig. 6b). The calculated residual circulation, which filters out the short-term $(<1 \mathrm{~d})$ tidal components, reveals the existence of a wellestablished central cyclonic gyre and a complex circulation pattern in the Goulet, with water entering and leaving the bay by the southern and northern sides of this narrow strait, respectively. The residual circulation leads to freshwater residence times in the bay typically between 10 and 20 d (Le Pape 1996).

\section{Transport}

Calibration of the dispersion coefficients $\left(D_{X^{\prime} y}\right)$ was performed using a set of salinity data from 1993 (not shown). Three salinity profiles collected in 2001 along a longitudinal transect within the Aulne estuary and the inner bay were then used for validation of the transport model (Fig. 7). In August and November 2001, river discharges from the Aulne River were low ( 10 and $\sim 5 \mathrm{~m}^{3} \mathrm{~s}^{-1}$, respectively). In contrast, May 2001 was characterized by much higher values $\left(\sim 50 \mathrm{~m}^{3} \mathrm{~s}^{-1}\right)$. Comparison between simulated and measured profiles reveals that, under low flow conditions characteristic of the summer period, the fully transient model properly captures the estuarine salt intrusion. A slightly larger deviation is observed in May 2001, which can be explained by the onset of a vertical stratification of the water masses in the vicinity of the estuarine mouth when river flow increases. The simulated depth-averaged salinities are therefore higher than the observed values collected $1 \mathrm{~m}$ below the water surface. Note, however, that the stratification is significant only in a small portion of the longitudinal transect within the estuary $(\sim 10 \mathrm{~km}$ into the bay from the Aulne's riverine boundary) and is generally negligible within the bay during the biologically productive period (Salomon \& Breton 1991, Le Pape 1996).

\section{Biogeochemistry}

\section{Seasonal dynamics}

The Bay of Brest and the estuaries are characterized by different hydrodynamic and transport regimes, and, therefore, by distinct biogeochemical behavior. In the following, the estuarine processes are only analyzed
Several smaller anti-cyclonic gyres characterized by significantly lower velocities also develop in the northern ment of large gyres in the center of the bay and very strong currents in the narrow strait connecting the bay to the ocean (Goulet). During the flood, the formation of the well-documented, large central cyclonic gyre (Salomon \& Breton 1991) can be identified in the model results. 
in the extensively surveyed Aulne estuary, which accounts for $80 \%$ of the annual water and nutrient discharges to the bay. The transition between the Aulne estuary and the bay can conveniently be located in the area where a sudden increase in cross section occurs (Terenez, Fig. 1b). In the estuary, the dynamics are essentially 1-dimensional and important concentration gradients are established along the longitudinal curvilinear axis of the system. In the bay, the spatial variability in the concentration fields is limited due to low river discharge and intense tidal mixing (Fig. 8). Field observations at various locations in the bay show, however, that seasonal changes in biogeochemical variables are significant.

Fig. 8 compares fully transient longitudinal profiles of dSi and DIN with measurements performed along the salinity gradient of the Aulne estuary in February, May, August and November 2001. Results show that the model captures the main features of the spatial and temporal distributions of nutrients in the estuary. The property-salinity plots reveal an almost conservative behavior, even during the biologically productive period. Transport and mixing are therefore always dominant over internal transformation processes. The dilution between the freshwater end-member and the water masses discharging in the bay provokes a 1 order of magnitude decrease in nutrient concentration.

Fig. 9a,b shows the simulated seasonal variations of dSi and DIN over the year 2001 at 2 locations (Stns R2 and R3, Fig. 1) in the bay. Stns R2 and R3 are representative of the dynamics in the southern basin and in the center of the bay, respectively (Jean 1994, Ragueneau et al. 1994, Le Pape et al. 1996, 1999). The 2 stations have been extensively surveyed since the 1990s (Le Pape 1996, Del Amo 1996, Chauvaud 1998, Lorrain 2002) and are currently sampled on a yearly basis. Nutrient distributions are characterized by high values during winter followed by a rapid decrease in late April at both stations (Fig. 9a,b), when estuarine discharge is reduced and biological uptake is promoted by an increase in temperature and incident solar radiation (Fig. 3). dSi is consumed slightly earlier in the season than DIN, the former remaining limiting for phytoplankton growth for at least 2 mo. Simulated nutrient concentrations increase again in the summer for dSi and only in the fall for DIN, in agreement with field observations.

The nutrient consumption in late April 2001 corresponds to the development of a diatom-dominated early spring bloom (Fig. 9c). The model predicts a switch from diatom to dinoflagellate dominance in August, in agreement with field observations (Chauvaud et al. 1998, Beucher et al. 2004). The occurrence of such late summer dinoflagellate blooms has recently been reported for the years 1995, 1998, 1999 and 2001

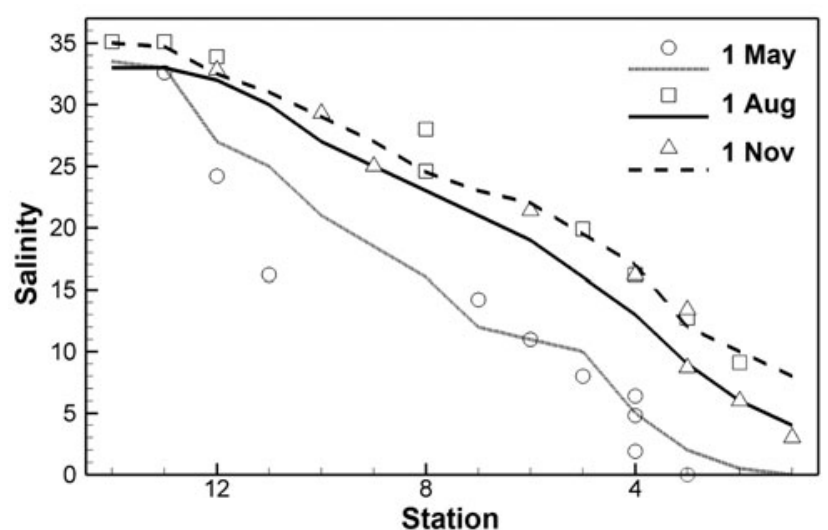

Fig. 7. Simulated (lines) and measured (points) transient longitudinal salinity profiles at various stations in the Aulne estuary for 3 river discharges $(Q)$ in 2001. May: $Q=15 \mathrm{~m}^{3} \mathrm{~s}^{-1}$, August: $Q=2 \mathrm{~m}^{3} \mathrm{~s}^{-1}$, November: $Q=30 \mathrm{~m}^{3} \mathrm{~s}^{-1}$

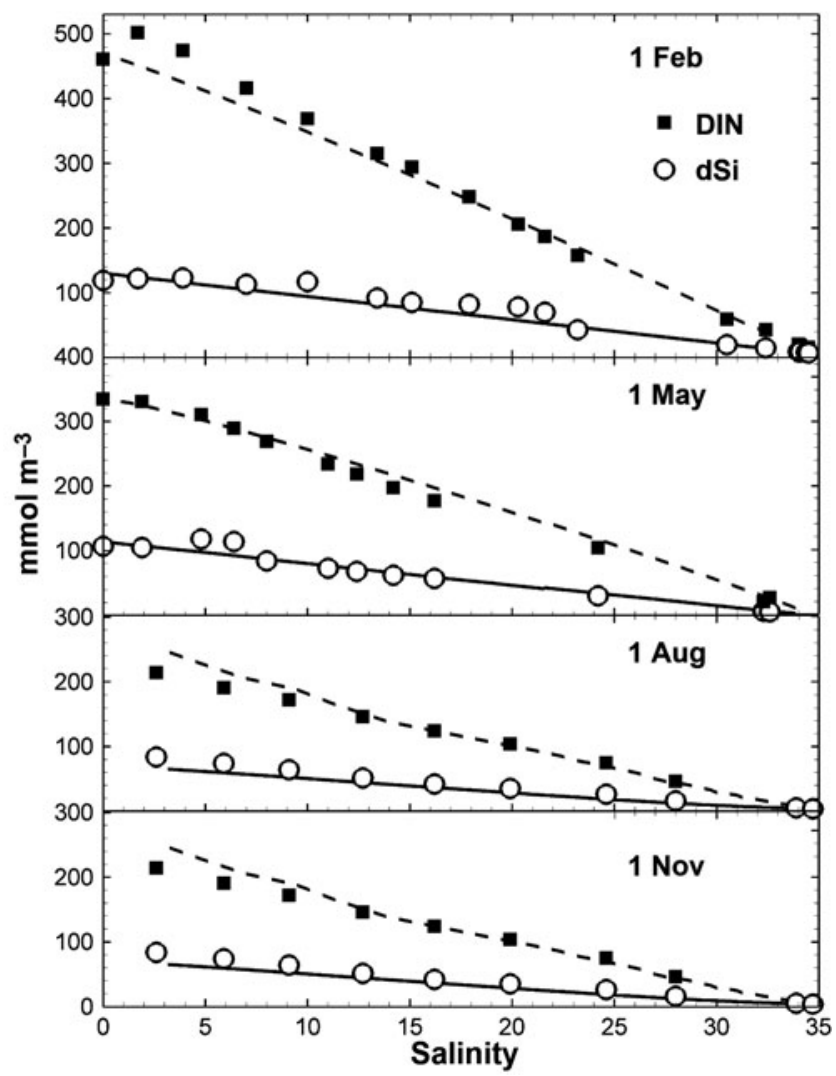

Fig. 8. Simulated (lines) and measured (points) transient longitudinal profiles of dissolved silica (dSi) and dissolved inorganic nitrogen (DIN) as a function of salinity in the Aulne estuary in February, May, August and November 2001

(Chauvaud et al. 1998, Lorrain 2002). The phytoplankton succession explains partly why, after the depletion period, dSi concentrations increase earlier in the season than DIN. This succession explains also high chl a concentrations from spring to fall and leads to a fairly 


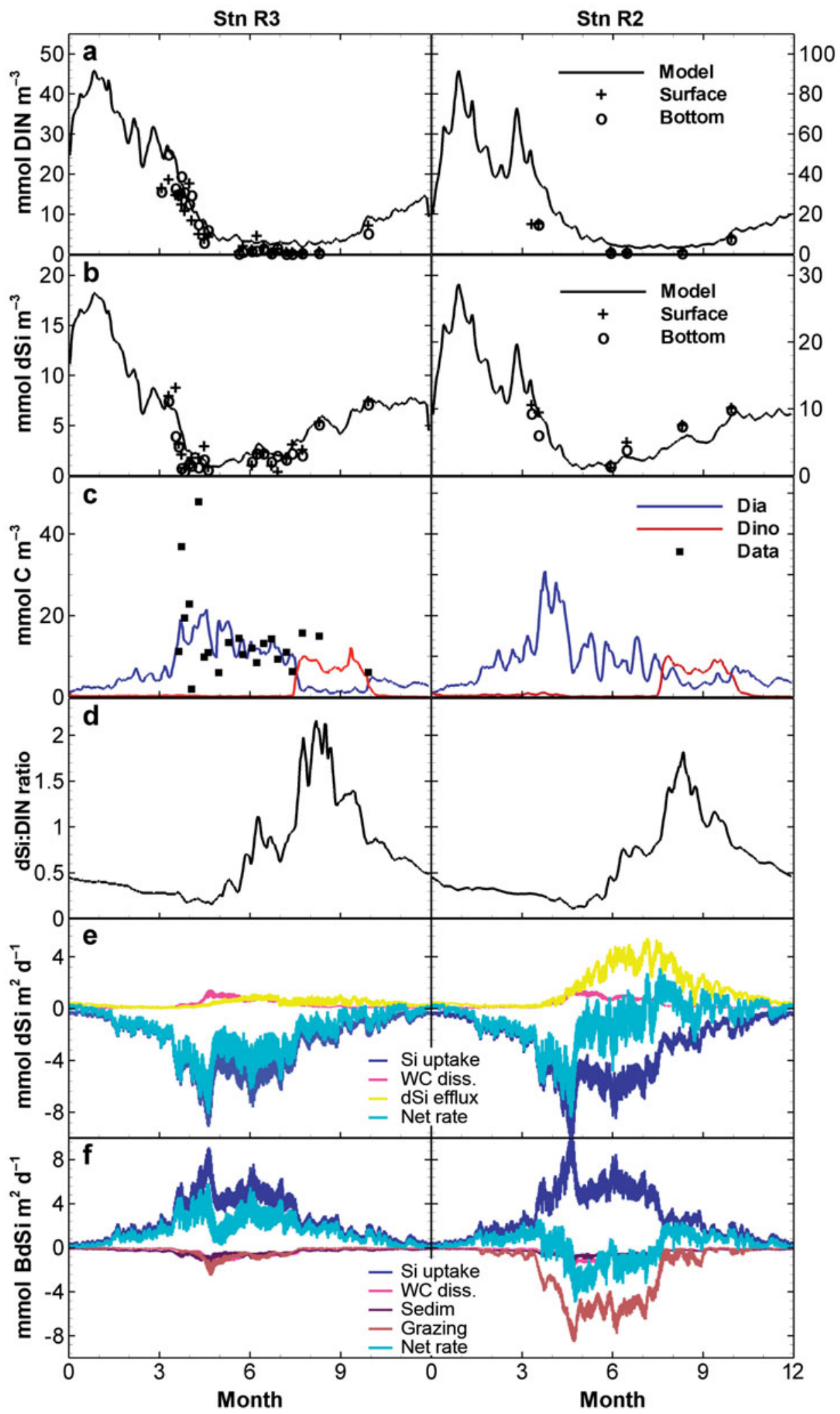

Fig. 9. Seasonal time course of (a) dissolved inorganic nitrogen (DIN), (b) dissolved silica (dSi), (c) phytoplankton biomass and (d) dSi:DIN ratio in the water column at Stns R3 (left) and R2 (right). Measured nutrient concentrations at the surface and the bottom of the Bay are also shown in (a) and (b). Chl a measurements in (c) were converted into carbon units. Process rates affecting the pelagic dSi and $\mathrm{bSiO}_{2}$ concentrations are illustrated in panels (e) and (f), respectively. WC diss.: water column dissolution; Sedim.: sedimentation rate. Net rate: sum of all positive and negative processes 
long productive period. Such dynamics differs from the conditions that prevailed in the years 1970 to 1980 when the first diatom spring bloom was usually of

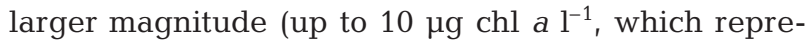

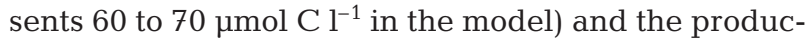
tive period of shorter duration (Chauvaud et al. 2000). The simulated dSi uptake by diatoms is in good agreement with in situ rate measurements based on ${ }^{32} \mathrm{Si}$ incorporation (Fig. 10a, Ragueneau et al. 2005), except for the 2 very high uptake rates recorded at the early stages of the productive period. This discrepancy might be attributed to the succession of distinct diatom species characterized by different $\mathrm{Si}$ C ratios, a feature not accounted for in the model. The observed phytoplankton which remained in the fall of 2001 (up to $1.5 \mu \mathrm{g} \mathrm{chl} \mathrm{a} \mathrm{l}^{-1}$, Lorrain 2002) when dSi uptake is low must be attributed to non-siliceous algal development, a result consistent with the simulated phytoplankton succession (Fig. 9c). As already reported in previous modeling studies (Monbet 1992, Pondaven et al. 1998), the zooplankton dynamics follows that of phytoplankton with a time lag of about $10 \mathrm{~d}$, consistent with a typical predator-prey relationship for this kind of ecosystem (data not shown).

The time course of water column variables at Stns R2 and R3 exhibits similar patterns and, thus, limited spatial variability in the pelagic dynamics. At these stations, the high density of filtering organisms leads to a benthic exchange flux through the sedimentwater interface of similar magnitude to the pelagic uptake of dSi. In contrast, the biomass of benthic filter feeders shows a high degree of heterogeneity over short distances (Fig. 1). The intra-annual variability in biomass of benthic filter feeders is of the order of 40 to $50 \%$, in agreement with previous modeling studies in the bay (Jean 1994, Grall et al. 2006). Typically, the seasonal time course of the biomass is characterized by a decrease during winter followed by a growth period between April and September and, during fall, a decrease back to the original winter conditions (Grall et al. 2006).

Fig. 9e,f compares the process rate distributions affecting $\mathrm{dSi}$ and $\mathrm{bSiO}_{2}$ at Stns R2 and R3. Model results reveal that the pelagic uptake of $\mathrm{dSi}$ and the dissolution of dead diatoms in the water column are of similar magnitude at both stations. Benthic processes show, however, a much larger variability: the grazing of diatoms by benthic filter feeders and the dSi efflux out of the sediments is roughly 1 order of magnitude higher at Stn R2. At this site, benthic exchanges through the sediment-water interface are of similar magnitude to the pelagic uptake of $\mathrm{dSi}$ due to the high density of filtering organisms. In contrast, the local dynamics at Stn R3 is by far dominated by the pelagic activity of the phytoplankton. As a result, the dynamic balance between processes always remains negative for dSi at this station, indicating continuous, net silica uptake over a seasonal cycle. The pattern in net rate is more complex at Stn R2 as a result of the dynamic interplay between pelagic production, grazing and benthic $\mathrm{bSiO}_{2}$ dissolution. The benthic flux of silica reaches values as high as $6 \mathrm{mmol} \mathrm{Si} \mathrm{m}{ }^{-2} \mathrm{~d}^{-1}$ and exceeds the dSi uptake during a large part of the productive period.

The magnitude and timing of this high recycling flux of $\mathrm{bSiO}_{2}$ is in good agreement with direct flux measurements based on sediment cores incubations (Fig. 10b, Ragueneau et al. 2005). The drop in dSi efflux in the absence of filtering organisms is also captured by our model, even though the seasonal variation in the simulated flux is of smaller magnitude than actually observed. The comparison between the pelagic dynamics at Stns R2 and R3 shows that the intense turbulent mixing leads to an homogenization of water column properties that does not reflect the spatial heterogeneity in benthic process intensities. Field observations focusing only on the time evolution of the
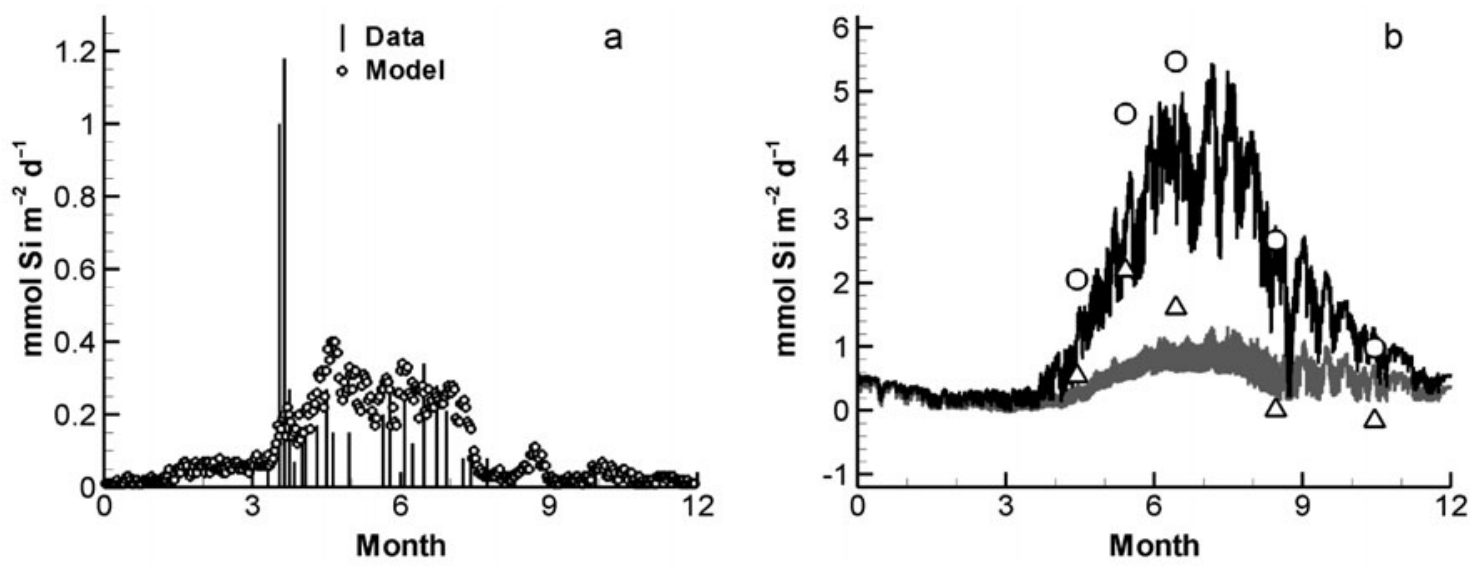

Fig. 10. (a) Simulated (points) and measured (vertical bars) pelagic dSi uptake rates. (b) Comparison of Si benthic fluxes through the sediment-water interface simulated (lines) and measured (points) at a station with (circles, black line) and without (triangles, grey line) Crepidula fornicata. Data from Ragueneau et al. (2005) 
pelagic variables (DIN, dSi and phytoplankton) are therefore of limited value to capture the biogeochemical dynamics in the Bay of Brest.

\section{Temporally resolved Si budget}

Fig. 11 presents a temporally resolved silica budget in the estuaries and the Bay of Brest for the year 2001. Each simulated process rate is integrated over the whole model domain, and then time-integrated over monthly periods. The extent of the benthic-pelagic coupling is summarized in Fig. 11a. The total deposition flux of BSi due to sedimentation and grazing remains roughly constant from May to July and reaches values up to $20 \times 10^{6} \mathrm{~mol} \mathrm{Si} \mathrm{\textrm {mo } ^ { - 1 }}$ (about $4 \mathrm{mmol} \mathrm{Si} \mathrm{m}{ }^{-2} \mathrm{~d}^{-1}$ ). The benthic recycling flux of dSi to the water column follows the deposition pulse with a time lag of 1 to 2 mo and reaches maximum values in August $\left(\sim 15 \times 10^{6} \mathrm{~mol} \mathrm{Si} \mathrm{mo}^{-1}\right.$ or $\left.3 \mathrm{mmol} \mathrm{Si} \mathrm{m}{ }^{-2} \mathrm{~d}^{-1}\right)$. Such a time lag falls within the range of benthic flux responses determined from a sensitivity analysis performed with a transient, vertically resolved, early dia- genetic model of silica (Arndt \& Regnier 2007). Yearly integrated deposition and recycling fluxes of silica amount to 0.56 and $0.48 \mathrm{~mol} \mathrm{Si} \mathrm{m}^{-2}$, respectively. The preservation of biogenic silica in the sediments after 1 yr of simulation represents $\sim 14 \%$ of the supply flux by riverine inputs.

The importance of benthic-pelagic coupling for the silica cycle in the water column of the bay is shown in Fig. 11b. Results reveal that the total dSi flux in the bay exceeds the uptake by diatoms during a significant fraction of the year. However, a reverse trend is observed between April and August which leads to a significant depletion of the total mass of dSi in the system during the productive period (Fig. 9c). The river input is larger than the recycling fluxes of $\mathrm{dSi}$ in the water column and in the sediments until May. From then onwards, the benthic-pelagic coupling becomes the main source of dSi to the water column until fall. At its maximum value in August, the benthic flux is roughly 1 order of magnitude larger than both river input and water column dissolution and sustains almost entirely the late summer diatom bloom in the bay. If one excludes the winter months, during which most of the
Fig. 11. Monthly resolved budget of $\mathrm{Si}$ for the Bay of Brest and the Aulne and Elorn estuaries. Fluxes from the baseline simulation are shown for the (a) benthic-pelagic exchange and (b) dSi processes in the water column. Results of the scenario without Crepidula fornicata (NoCF) are presented in (c) and (d). Monthly resolved masses of diatom and dinoflagellate biomasses in the system are shown for the (e) baseline and (f) NoCF simulations

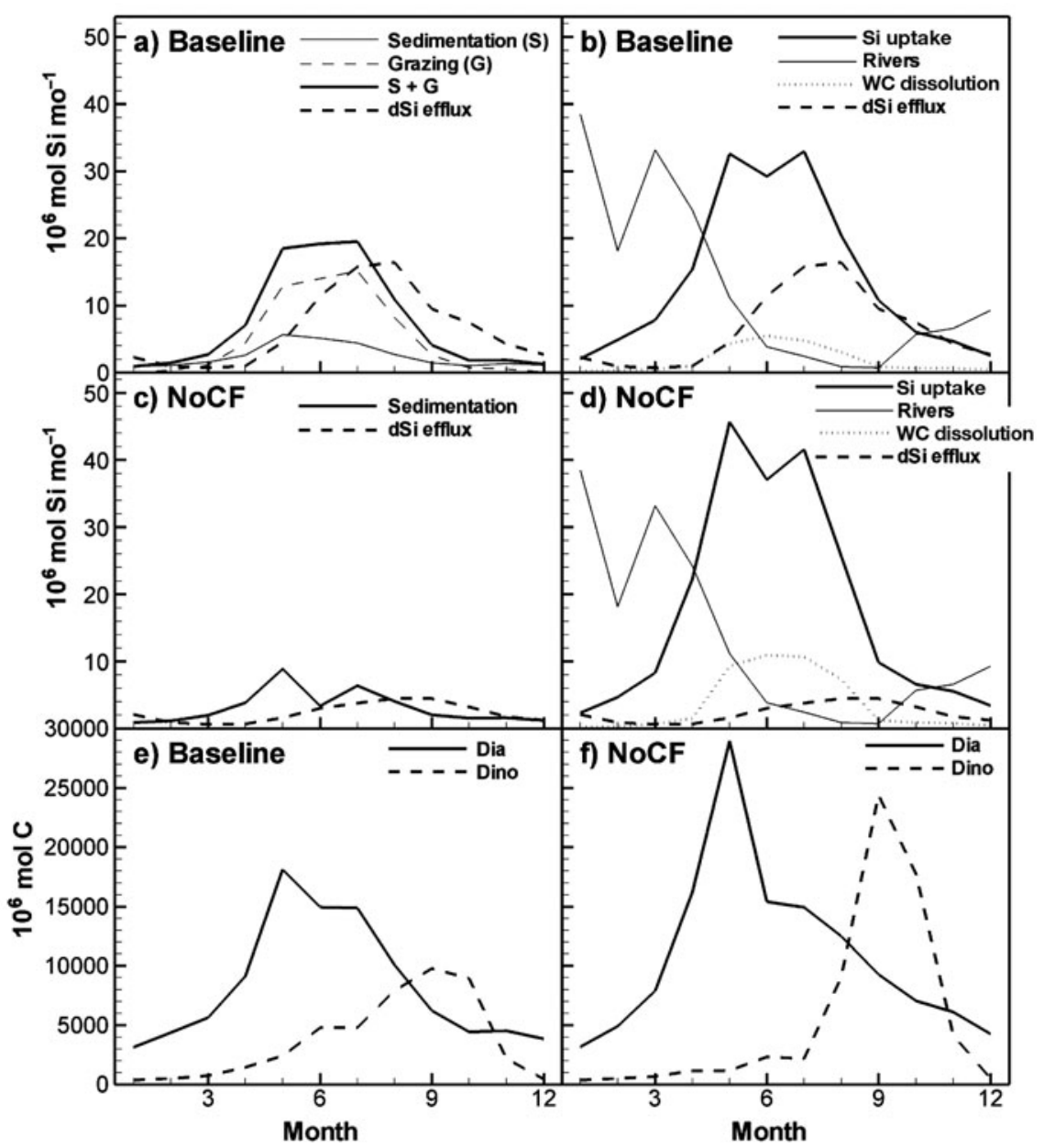


$\mathrm{dSi}$ is transported as a passive tracer through the system (freshwater residence times $\sim 10 \mathrm{~d}$ for a typical winter river discharge), the relative contributions of the benthic flux, the river input and the water column dissolution to the dSi supply during the period April to September amount to 48,36 and $16 \%$, respectively. Therefore, benthic-pelagic coupling sustains an important part of the annual diatom productivity in the bay.

The monthly resolved budgets can be integrated and compared with previously established seasonal budgets during the winter/fall and spring/summer periods of 2001 (Ragueneau et al. 2005). The seasonal budgets were constructed from local measurements of silica production and dissolution in the water column, as well as from experimentally derived dSi benthic fluxes through the sediment-water interface. The extrapolation for the production flux was based on weekly surveys performed at a single site (Stn R3). The agreement with the model predictions is nevertheless satisfactory, a result which can be explained by the fairly homogeneous dSi uptake rates over the entire area of the bay. Overall agreement in dSi benthic flux estimates is also achieved and reflects the dominant control of Crepidula fornicata on the magnitude of these fluxes, a factor which was already accounted for in the experimentally derived budgets (Ragueneau et al. 2005). A larger discrepancy is obtained for the deposition flux, the yearly integrated estimates agreeing within $30 \%$. The winter/fall prediction from the model is only about half that of Ragueneau et al. (2005), yet because most of the internal Si cycling in the bay occurs during the spring/summer period, this variability has a limited effect at the yearly time scale.

The most important deviation between estimates is obtained for the water column dissolution. The modelbased calculations suggest that this process accounts for only $13 \%$ of the annual Si production, whereas the estimate from direct measurements by Beucher et al. (2004) leads to a significantly higher relative contribution (45\%). Interestingly, a similar discrepancy between the estimates of Beucher et al. (2004) and those established by mass balance calculations (18\%) was already reported by Ragueneau et al. (2005) and attributed to the fact that the direct measurements represent a (maximum) potential dissolution flux from the diatom community if they were to remain permanently in suspension in the water column. However, the Bay of Brest is very shallow and diatoms settle rapidly; therefore, they are being heavily grazed by suspension feeders, and the magnitude of the modelderived pelagic dissolution should logically be smaller than the experimentally derived estimate. Obviously, a significant fraction of the preserved diatoms will actually dissolve in the sediments. However, as already discussed above, it is important to obtain accurate esti- mates of the relative contribution of water column and benthic dissolution fluxes as this factor is instrumental for the determination of the time delays in Si dynamics and, thus, for the phytoplankton dynamics in the bay.

\section{Reduction in biomass of benthic filter feeders}

The model is used here for prognostic purposes and is a first attempt at quantifying the effect of eradicating an invasive benthic filter feeder on the Si dynamics and phytoplankton succession in the bay. Fig. 11c shows the magnitude of the benthic-pelagic coupling in a scenario without Crepidula fornicata (referred to as NoCF) and should be compared with the results of the baseline simulation discussed above (Fig. 11a,b). Simulations reveal that in the NoCF scenario, the supply flux of $\mathrm{bSiO}_{2}$ to the sediments and the dSi flux back to the water column are both significantly smaller than in the baseline run. On a yearly integrated basis, the amount of $\mathrm{bSiO}_{2}$ reaching the benthic compartment decrease from $89 \times 10^{6}$ to $37 \times 10^{6} \mathrm{~mol} \mathrm{yr}^{-1}$ when the benthic filter feeders are removed. Although removing the grazing term leads to a slightly higher sedimentation flux $(+29 \%)$ in the NoCF scenario, this increase does not compensate for uptake by the grazers and, therefore, the dSi efflux is roughly 3 times smaller in this case.

The effect of the benthic-pelagic coupling on the amount of dSi available to sustain the pelagic primary production is summarized in Fig. 11d. In the baseline simulation, the benthic dSi flux to the bay is largely dominant from early June until November, the riverine inputs contributing most during the winter period. In the NoCF case, the benthic return flux remains small throughout the year. Yet, because of the increased residence time of the phytoplankton within the water column (both living and dead), the pelagic dissolution of dead diatoms is twice as large during most of the summer period, and partly compensates for the drop in benthic flux. A major difference between both scenarios, however, is the overall reduction of the dSi flux during late summer and fall, which was mainly sustained by the time-delayed efflux from the sediments in the baseline simulation.

The temporal distribution of dSi uptake (Fig. 11d) and phytoplankton succession (Fig. 11e,f) partly reflects the variation in dSi supply when benthic filter feeders are removed from the seabed. In the NoCF scenario, results reveal that during the spring/early summer, when the total dSi inputs from the various sources are already reduced but not limiting, both the Si uptake and the total diatom biomass are increased compared to the baseline simulation. Such behavior might appear counterintuitive but can be explained by the 
significantly larger residence times of living diatoms in the bay when the sink term due to grazing is suppressed. As a result, the total diatom biomass, which develops during the April to July period, increases by $32 \%$ in the NoCF scenario. Results also reveal a more distinct phytoplankton succession when the influence of the benthic-pelagic coupling is reduced. In the NoCF case, the total biomass of dinoflagellates is up to twice that of the baseline scenario. The hypothesis that an engineered intervention aiming at removing Crepidula fornicata from the bay might sustain enhanced harmful dinoflagellate blooms is thus supported by the results of the present study.

\section{CONCLUSIONS}

A reactive-transport modeling approach has been used to identify and quantify the dominant pelagic and benthic processes of the Si cycle in the Bay of Brest and the Aulne and Elorn estuaries. The simulations resolved the seasonal variations in process intensities and helped unravel the role of the benthic filter feeders in the magnitude and timing of the benthic-pelagic coupling in this shallow coastal ecosystem. Hydrodynamics and transport results showed that the dominant physical controls on biological processes were properly represented in our numerical model. The biogeochemical dynamics in the estuaries revealed limited biogeochemical transformation but significant dilution upon estuarine mixing. In the bay, the model results were in good agreement with the measured seasonal evolution in nutrient concentration, dSi uptake and benthic fluxes. Simulations revealed that the intense mixing in the bay limits the spatial variability in the pelagic phytoplankton dynamics. In contrast, the benthic processes showed a high degree of heterogeneity which is correlated with the spatial distribution of benthic filter feeders. The magnitude of the benthic efflux of $\mathrm{dSi}$ to the water column can vary by up to 1 order of magnitude and, in areas densely populated by Crepidula fornicata, it may reach values comparable to the local uptake by diatoms in the overlying water column. The dSi efflux also followed the deposition pulse with a typical time lag of 1 to 2 mo and, on a yearly basis, preservation of $\mathrm{bSiO}_{2}$ remained limited. Our model approach was particularly suitable to provide temporally resolved Si budgets for the entire bay and estuarine areas. Results revealed that the benthic recycling fluxes of dSi during the productive period was the main source $(40 \%)$ of this nutrient to the bay and sustained almost entirely the late summer diatom bloom. A prognostic scenario of reduction in biomass of benthic filter feeders revealed that the magnitude and timing of the pelagic diatom bloom is only moder- ately affected by the decrease in intensity of the benthic-pelagic coupling. On the other hand, the hypothesis that the removal of the filtering organisms on the seabed might enhance the development of harmful dinoflagellate blooms in the bay is supported by our model results.

Acknowledgments. This work was financially supported by the EU-RTN Si-WEBS (contract number HPRN-CT-2002000218), by the Netherlands Organization for Scientific Research (NWO) (VIDI award 864.05.007 to P.R.) and by the government of the Brussels-Capital region (Brains Back to Brussels award to P.R.).

\section{LITERATURE CITED}

Abbott MB (1979). Computational hydraulics: elements of the theory of free surface flows. Pitman, London

Andersen V (1985) Modélisation d'écosystèmes pélagiques. Étude de processus. PhD thesis, Université Pierre et Marie Curie, Paris

Andersen V, Nival P (1988) A pelagic ecosystem model simulating production and sedimentation of biogenic particules: role of salps and copepods. Mar Ecol Prog Ser 44:37-50

Antia NJ, McAllister CD, Parsons TR, Stephens K, Strickland JDH (1963) Further measurements of primary production using a large-volume plastic sphere. Limnol Oceanogr 8: 166-183

Arndt S, Regnier P (2007) A model for the benthic-pelagic coupling of silica in estuarine ecosystems: sensitivity analysis and system scale simulation. Biogeosciences 4:331-352

Arndt S, Vanderborgth JP, Regnier P (2007) Diatom growth response to physical forcing in a macrotidal estuary: coupling hydrodynamics, sediment transport and biogeochemistry. J Geophys Res 12. doi:10.1029/2006JC003581

> Baretta-Bekker JG, Riemann B, Baretta JW, Rasmussen EK (1994) Testing the microbial loop concept by comparing mesocosm data with results from a dynamical simulation model. Mar Ecol Prog Ser 106:187-198

Beucher C, Tréguer P, Corvaisier R, Hapette AM, Elskens M (2004) Production and dissolution of biosilica, and changing microphytoplankton dominance in a coastal ecosystem of western Europe. Mar Ecol Prog Ser 267:57-69

Chapelle A (1991) Modélisation d'un écosystème marin cier soumis à l'eutrophisation: la baie de Vilaine (sud Bretagne). Etude du phytoplancton et du bilan en oxygène. $\mathrm{PhD}$ thesis, Université Pierre et Marie Curie, Paris

Chauvaud L (1998) La coquille Saint-Jacques en Rade de Brest: un modèle biologique d'étude des réponses de la faune benthique aux fluctuations de l'environnement. $\mathrm{PhD}$ thesis, Université de Bretagne Occidentale, Brest

Chauvaud L, Thouzeau G, Paulet YM (1998) Effects of environmental factors on the daily growth rate of Pecten maximus juveniles in the Bay of Brest (France). J Exp Mar Biol Ecol 227:83-111

Chauvaud L, Jean F, Ragueneau O, Thouzeau G (2000) Longterm variation of the Bay of Brest ecosystem: benthicpelagic coupling revisited. Mar Ecol Prog Ser 200:35-48

Cloern JE (2001) Our evolving conceptual model of the coastal eutrophication problem. Mar Ecol Prog Ser 210: 223-253

Conley DJ, Schelske CL, Stoermer EF (1993) Modification of the biogeochemical cycle of silica with eutrophication. Mar Ecol Prog Ser 101:179-192 
Del Amo Y (1996) Dynamique et structure des communautés phytoplanctoniques en écosystème côtier perturbé; cinétiques de l'incorporation du silicium par les diatomées. $\mathrm{PhD}$ thesis, Université de Bretagne Occidentale, Brest

$>$ Del Amo Y, Le Pape O, Tréguer P, Quéguiner B, Menesguen A, Aminot A (1997a) Impacts of high-nitrate freshwater inputs on macrotidal ecosystems. I. Seasonal evolution of nutrient limitation for the diatom-dominated phytoplankton of the Bay of Brest (France). Mar Ecol Prog Ser 161:213-224

Del Amo Y, Quéguiner B, Tréguer P, Breton H, Lampert L (1997b) Impacts of high-nitrate freshwater inputs on macrotidal ecosystems. II. Specific role of the silicate pump in the year-round dominance of diatoms in the Bay of Brest (France). Mar Ecol Prog Ser 161:225-237

Dugdale RC, Wilkerson FP, Minas HJ (1995) The role of a silicate pump in driving new production. Deep-Sea Res I 42:697-719

Ekebjærg L, Justesen P (1991) An explicit scheme for advection-diffusion modelling in two dimensions. Comput Methods Appl Mech Eng 88:3-8

Eppley RW (1972) Temperature and phytoplankton growth in the sea. Fish Bull 70:1063-1085

Fouillaron P, Leynaert A, Claquin P, L'Helguen S and others (2007) Response of a phytoplankton community to increased nutrient inputs: a mesocosm experiment in the Bay of Brest (France). J Exp Mar Biol Ecol 351:188-198

Grall J, Le Loc'h F, Guyonnet B, Riera P (2006) Community structure and food web based on stable isotopes $\left(\delta^{15} \mathrm{~N}\right.$ and $\delta^{13} \mathrm{C}$ ) analysis of a North Eastern Atlantic maerl bed. J Exp Mar Biol Ecol 338:1-15

Guarini JM, Sari N, Moritz C (2008) Modelling the dynamics of the microalgal biomass in semi-enclosed shallow-water ecosystems. Ecol Model 211:267-278

Guérin L (2004) La crépidule en rade de Brest: un modèle biologique d'espèce introduite proliférante en réponse aux fluctuations de l'environnement. PhD thesis, Université de Bretagne Occidentale, Brest

Jean F (1994) Modélisation à l'état stable des transferts de carbone dans le rè seau trophique benthique de la Rade de Brest (France). PhD thesis, Université de Bretagne Occidentale, Brest

Jean F, Thouzeau G (1995) Estimation des variables d'etat d'un modele de reseau trophique benthique en rade de Brest. C R Acad Sci Paris Sci Vie 318:145-154

Le Pape O (1996) Modélisation des cycles biogéochimiques des éléments limitant la production phytoplanctonique en rade de Brest. PhD thesis, Ecole Nationale supérieure d'Agronomie de Rennes

- Le Pape O, Del Amo Y, Ménesguen A, Aminot A, Quéguiner B, Tréguer P (1996) Resistance of a costal ecosystem to increasing eutrophic conditions: the Bay of Brest (France), a semi-enclosed zone of Western Europe. Cont Shelf Res 16: 1885-1907

Le Pape O, Jean F, Ménesguen A (1999) Pelagic and benthic trophic chain coupling in a semi-enclosed coastal system, the Bay of Brest (France): a modelling approach. Mar Ecol Prog Ser 189:135-147

Lorrain A (2002) Les structures calcifiées des invertébrés marins témoins des fluctuations de l'environnement côtier. $\mathrm{PhD}$ thesis, Université de Bretagne Occidentale, Brest

Margalef R (1978) Life-forms of phytoplankton as survival alternatives in an unstable environment. Oceanol Acta 1: 493-509

> Martin S, Clavier J, Chauvaud L, Thouzeau G (2007) Community metabolism in temperate maerl beds. II. Nutrient fluxes. Mar Ecol Prog Ser 335:31-41

Monbet Y (1992) Control of phytoplankton biomass in estuar- ies: a comparative analysis of microtidal and macrotidal estuaries. Estuaries 15:563-571

Moriceau B (2002) La dissolution de la silice biogé nique dans la Rade de Brest: influence des crépidules. MS thesis, Université de Bretagne Occidentale, Brest

Officer CB, Ryther JH (1980) The possible importance of silicon in marine eutrophication. Mar Ecol Prog Ser 3:83-91

Paasche E (1973) Silicon and the ecology of marine plankton diatoms: II. Silicate-uptake kinetics in five diatom species. Mar Biol 19:262-269

Pondaven P, Fravalo C, Ruiz-Pino D, Tréguer P, Quéguiner B, Jeandel C (1998) Modelling the silica pump in the permanently open ocean zone of the Southern Ocean. J Mar Syst 17:587-618

Radach G, Moll A (1993) Estimation of the variability of production by simulating annual cycles of phytoplankton in the central North Sea. Prog Oceanogr 31:339-419

Ragueneau O (1994) La dynamique du phytoplancton en écosystèmes macrotidaux: couplage avec l'hydrodynamique et le cycle biogéochimique du silicium. PhD thesis, Université de Bretagne Occidentale, Brest

> Ragueneau O, De Blas Varela E, Tréguer P, Quéguiner B, Del Amo Y (1994) Phytoplankton dynamics in relation to the biogeochemical cycle of silicon in a coastal ecosystem of western Europe. Mar Ecol Prog Ser 106:157-172

Ragueneau O, Quéguiner B, Tréguer P (1996) Contrast in biological responses to tidally induced vertical mixing for two macrotidal ecosystems of Western Europe. Estuar Coast Shelf Sci 42:645-665

Ragueneau O, Chauvaud L, Leynaert A, Thouzeau G and others (2002) Direct evidence of a biologically active coastal silicate pump: ecological implications. Limnol Oceanogr 47:1849-1854

Ragueneau O, Chauvaud L, Moriceau B, Leynaert A, Thouzeau G, Donval A, Le Loc'h F, Jean F (2005) Biodeposition by an invasive suspension feeder impacts the biogeochemical cycle of $\mathrm{Si}$ in a coastal ecosystem (Bay of Brest, France). Biogeochem 75:19-41

Ragueneau O, Conley DJ, Ni Longphuirt S, Slomp C, Leynaert A (2006a) A review of the Si biogeochemical cycle in coastal waters, I: diatoms in coastal food webs and the coastal Si cycle. In: Ittekkot V, Humborg C, Garnier J (eds) Land-ocean nutrient fluxes: silica cycle. SCOPE Book, Island Press, Washington, DC, p 163-195

Ragueneau O, Conley DJ, Ni Longphuirt S, Slomp C, Leynaert A (2006b) A review of the Si biogeochemical cycle in coastal waters, II: anthropogenic perturbation of the $\mathrm{Si}$ cycle and responses of coastal ecosystems. In: Ittekkot $\mathrm{V}$, Humborg C, Garnier J (eds), Land-ocean nutrient fluxes: silica cycle. SCOPE Book, Island Press, Washington, DC, p 197-213

Redfield AC (1934) On the proportions of organic derivations in sea water and their relation to the composition of plankton. In: Daniel RJ (ed) James Johnson Memorial Volume. University Press of Liverpool, p 177-192

Richard J (2005) Crepidula fornicata: un modèle biologique pour l'étude du rôle de la variabilité des caractères phénotypiques (reproduction, croissance et nutrition) sur les processus de colonisation en milieu marin. PhD thesis, Université de Genève

> Roberts EC, Davidson K, Gilpin LC (2003) Response of temperate microplankton communities to N:Si ratio perturbation. J Plankton Res 25:1485-1495

> Rousseau V, Leynaert A, Daoud N, Lancelot C (2002) Diatom succession, silicification and silicic acid availability in Belgian coastal waters (Southern North Sea). Mar Ecol Prog Ser 236:61-73 
Salomon JC, Breton M (1991) Numerical study of the dispersive capacity of the Bay of Brest, France, towards dissolved substances. In: Lee Cheung (ed) Environmental hydraulics. A. A. Balkema, Rotterdam, p 459-464

Smagorinsky J (1963) General circulation experiments with the primitive equations. Mon Weather Rev 91:99-164

Smayda TJ (1990) Novel and nuisance phytoplankton blooms in the sea: evidence for a global epidemic. In: Graneli E, Sundström B, Edler L, Anderson DM (eds) Toxic marine phytoplankton. Elsevier, Amsterdam, p 29-40

Smith SJ, Bank LC (1992) Modifications to beam theory for bending and twisting of open section composite beams: experimental verification. Compos Struct 22:169-177
Turner RE, Qureshi N, Rabalais NN, Dortch Q, Justic D, Shaw RF, Cope J (1998) Fluctuating silicate:nitrate ratios and costal plankton food webs. Proc Natl Acad Sci USA 95: 13048-13051

Van Cappellen P, Dixit S, Van Beusekom J (2002) Biogenic silica dissolution in the oceans: reconciling experimental and field-based dissolution rates. Global Biogeochem Cycles 16(4):1075, doi:10.1029/2001GB001431

Vanderborght JP, Folmer I, Aguilera DR, Uhrenholdt T, Regnier P (2007) Reactive-transport modelling of a river-estuarine-coastal zone system: application to the Scheldt estuary. Mar Chem 106:92-110

Von Liebig J (1840) Die organische Chemie in ihrer Anwendung auf Agrikultur und Physiologie. Friedrich Vieweg

Appendix 1. Parameters of the model and differential equations describing each state variable. See Table 1 for state variable abbreviations

\begin{tabular}{|c|c|c|c|c|}
\hline Symbol & Description & Value & Units & Source \\
\hline$k_{\mathrm{NDet}}$ & NDet mineralisation rate at $0^{\circ} \mathrm{C}$ in the water column & 0.03 & $\mathrm{~d}^{-1}$ & Baretta-Bekker et al. (1994) \\
\hline$k_{\mathrm{SiDet}}$ & SiDet mineralisation rate at $0^{\circ} \mathrm{C}$ in the water column & 0.06 & $\mathrm{~d}^{-1}$ & Le Pape (1996) \\
\hline$V_{\text {sed }}$ & Sedimentation rate for Dia and detritic matter & 1.5 & $\mathrm{~mol} \mathrm{C} \mathrm{l}^{-1}$ & Andersen \& Nival (1988) \\
\hline$k d_{\text {FDDia }}$ & FDDia degradation rate to detritic matter & 0.1 & $\mathrm{~d}^{-1}$ & Le Pape (1996) \\
\hline$k d_{\mathrm{BFDDia}}$ & BFDDia degradation rate to detritic matter & 0.1 & $\mathrm{~d}^{-1}$ & Le Pape (1996) \\
\hline$\mu_{\text {maxDia }}$ & Maximum growth rate at $0^{\circ} \mathrm{C}$ for Dia & 0.5 & $\mathrm{~d}^{-1}$ & Chapelle (1991 ) \\
\hline$I_{\text {optDia }}$ & Optimal light intensity for Dia & 100 & $\mathrm{~W} \mathrm{~m}{ }^{-2}$ & Andersen (1985) \\
\hline$I_{\text {optDino }}$ & Optimal light intensity for Dino & 140 & $\mathrm{~W} \mathrm{~m} \mathrm{~m}^{-2}$ & Andersen (1985) \\
\hline$k N_{\text {Dia }}$ & Half saturation constant for $\mathrm{N}$ for Dia & 2 & $\mu \mathrm{mol} \mathrm{N} \mathrm{l^{-1 }}$ & Eppley (1972) \\
\hline$k N_{\text {Dino }}$ & Half saturation constant for $\mathrm{N}$ for Dino & 2 & $\mu \mathrm{mol} \mathrm{N} \mathrm{l^{-1 }}$ & Le Pape (1996) \\
\hline$k S i_{\text {Dia }}$ & Half saturation constant for Si for Dia & 1 & $\mu \mathrm{mol} \mathrm{N} \mathrm{l^{-1 }}$ & Paasche (1973) \\
\hline$\eta_{\text {Dia }}$ & Mortality rate at $0^{\circ} \mathrm{C}$ for Dia & 0.02 & $\mathrm{~d}^{-1}$ & Andersen (1985) \\
\hline$\eta_{\text {Dino }}$ & Mortality rate at $0^{\circ} \mathrm{C}$ for Dino & 0.02 & $\mathrm{~d}^{-1}$ & Radach \& Moll (1993) \\
\hline$\mu_{\text {maxDino }}$ & Maximum growth rate at $0^{\circ} \mathrm{C}$ for Dino & 0.4 & $\mathrm{~d}^{-1}$ & Calibration \\
\hline $\mathrm{C}: \mathrm{N}$ & $\mathrm{C}: \mathrm{N}$ ratio for phytoplankton & 6.62 & $\mathrm{~mol} \mathrm{C} \mathrm{mol} \mathrm{N}{ }^{-1}$ & Redfield (1934) \\
\hline $\mathrm{Si}: \mathrm{N}$ & Si:N ratio for phytoplankton & 1 & - & Redfield (1934) \\
\hline $\mathrm{N}: \operatorname{chl} a$ & $\mathrm{~N}: \mathrm{chl}$ a ratio for phytoplankton & 1 & - & Antia et al. (1963) \\
\hline$K_{\mathrm{nc}}$ & Non-chlorophilian light extinction coefficient & 0.1 & - & Calibration \\
\hline 1 & $\begin{array}{l}\text { Maximum depth over which the sedimentation rate is } \\
\text { maximum }\end{array}$ & 30 & $\mathrm{~m}$ & Le Pape (1996) \\
\hline$k_{\text {BNDet }}$ & BNDet mineralisation rate at $0^{\circ} \mathrm{C}$ in the sediment & 0.003 & $\mathrm{~d}^{-1}$ & Le Pape (1996) \\
\hline$k_{\mathrm{BSiDet}}$ & Si mineralisation rate at $0^{\circ} \mathrm{C}$ in the sediment & 0.006 & $\mathrm{~d}^{-1}$ & Moriceau (2002) \\
\hline$k_{\text {diffSi }}$ & Diffusion coefficient for $\mathrm{Si}$ & 0.0001 & - & Calibration \\
\hline$k_{\text {diffN }}$ & Diffusion coefficient for $\mathrm{N}$ & 0.0001 & - & Calibration \\
\hline$\varepsilon_{\text {Dia }}$ & Egestion rate of Ben for Dia & 0.4 & - & Le Pape et al. (1999) \\
\hline$\varepsilon_{\text {NDet }}$ & Egestion rate of Ben for Detritic matter & 0.8 & - & Le Pape et al. (1999) \\
\hline$\varepsilon_{\mathrm{BDia}}$ & Egestion rate of Ben for BDia & 0.4 & - & Le Pape et al. (1999) \\
\hline$\varepsilon_{\text {Dino }}$ & Egestion rate of Ben for Dino & 0.4 & - & Le Pape et al. (1999) \\
\hline Aff & Affinity of benthic feeders for Dia & 0.35 & - & Calibration \\
\hline Aff & Affinity of benthic feeders for Dino & 0.35 & - & Calibration \\
\hline$A f f_{\mathrm{BDia}}$ & Affinity of benthic feeders for BDia & 0.3 & - & Calibration \\
\hline$A f f_{\text {NDet }}$ & Affinity of benthic feeders for detritic matter & 0 & - & Calibration \\
\hline$S_{\text {minDia }}$ & Minimum slope of predation rate for Ben on Dia & 3 & $\mathrm{mmol} \mathrm{C} \mathrm{m}{ }^{-3}$ & Calibration \\
\hline$S_{\operatorname{maxDia}}$ & Maximum slope of predation rate for Ben on Dia & 11 & $\mathrm{mmol} \mathrm{C} \mathrm{m}{ }^{-3}$ & Calibration \\
\hline$S_{\operatorname{minDino}}$ & Minimum slope of predation rate for Ben on Dino & 3 & $\mathrm{mmol} \mathrm{C} \mathrm{m}{ }^{-3}$ & Calibration \\
\hline$S_{\text {maxDino }}$ & Maximum slope of predation rate for Ben on Dino & 11 & $\mathrm{mmol} \mathrm{C} \mathrm{m}{ }^{-3}$ & Calibration \\
\hline$S_{\text {minBDia }}$ & Minimum slope of predation rate for Ben on BDia & 200 & $\mathrm{mmol} \mathrm{C} \mathrm{m}{ }^{-2}$ & Calibration \\
\hline$S_{\text {maxBDia }}$ & Maximum slope of predation rate for Ben on BDia & 500 & $\mathrm{mmol} \mathrm{C} \mathrm{m}{ }^{-2}$ & Calibration \\
\hline$S_{\text {minBen }}$ & Ben biomass below which grazing stops & 3000 & $\mathrm{mmol} \mathrm{C} \mathrm{m} \mathrm{m}^{-2}$ & Calibration \\
\hline$S_{\text {maxBen }}$ & Saturation threshold for Ben & 18000 & $\mathrm{mmol} \mathrm{C} \mathrm{m}{ }^{-2}$ & Calibration \\
\hline$\eta_{\text {Ben }}$ & Mortality rate at $0^{\circ} \mathrm{C}$ for Ben & 0.0005 & $\mathrm{~d}^{-1}$ & Calibration \\
\hline
\end{tabular}


Appendix 1 (continued)

\begin{tabular}{|c|c|c|c|c|}
\hline Symbol & Description & Value & Units & Source \\
\hline$\rho_{\text {Ben }}$ & Excretion rate at $0^{\circ} \mathrm{C}$ for Ben & 0.0005 & $d^{-1}$ & Calibration \\
\hline$\tau_{\mathrm{Ben}}$ & Maximum ingestion rate at $0^{\circ} \mathrm{C}$ for Ben & 0.017 & $d^{-1}$ & Le Pape et al. (1996) \\
\hline$p_{\text {Dia }}$ & Affinity for Dia by Zoo & 0.5 & - & Pondaven et al. (1998) \\
\hline$p_{\text {Dino }}$ & Affinity for Dino by Zoo & 0.5 & - & Pondaven et al. (1998) \\
\hline$K_{\text {Zoo }}$ & Half saturation constant for chlorophyll for Zoo & 4.6 & & Pondaven et al. (1998) \\
\hline$\eta_{\text {Zoo }}$ & Maximum mortality rate at $0^{\circ} \mathrm{C}$ for Zoo & 0.06 & $d^{-1}$ & Pondaven et al. (1998) \\
\hline$\rho_{\text {Zoo }}$ & Excretion rate at $0^{\circ} \mathrm{C}$ for Zoo & 0.01 & $d^{-1}$ & Pondaven et al. (1998) \\
\hline$\varepsilon_{\text {Zoo }}$ & Egestion rate for Zoo & 0.4 & - & Pondaven et al. (1998) \\
\hline$m_{0}$ & Minimum mortality rate for Zoo & 0 & $\mathrm{~d}^{-1}$ & Pondaven et al. (1998) \\
\hline$m_{\mathrm{dd}}$ & Density-dependent mortality rate for Zoo & 0.0002 & $d^{-1}$ & Pondaven et al. (1998) \\
\hline bur $r_{\mathrm{BSiDet}}$ & Accumulation rate within the sediment for BSiDet & 0.003 & & Calibration \\
\hline bur $r_{\text {BNDet }}$ & Accumulation rate within the sediment for BNDet & 0.003 & & Calibration \\
\hline$k S i_{\text {BDia }}$ & Half saturation constant for Si for BDia & 1 & & Calibration \\
\hline$k N_{\text {BDia }}$ & Half saturation constant for $\mathrm{N}$ for BDia & 2 & & Calibration \\
\hline$I_{\text {optBDia }}$ & Optimal light intensity for BDia & 100 & $\mathrm{~W} \mathrm{~m}^{-2}$ & Calibration \\
\hline$\mu_{\text {maxBDia }}$ & Maximum growth rate at $0^{\circ} \mathrm{C}$ for BDia & 0.25 & $\mathrm{~d}^{-1}$ & Calibration \\
\hline$\eta_{\mathrm{BDia}}$ & Mortality rate at $0^{\circ} \mathrm{C}$ for BDia & 0.02 & $\mathrm{~d}^{-1}$ & Calibration \\
\hline$E_{\text {app }}$ & Activation energy of the Arrhenius function & 60 & $\mathrm{~kJ} \mathrm{~mol}^{-1}$ & Van Cappellen et al. (2002) \\
\hline $\mathrm{R}^{\mathrm{app}}$ & Gas constant & 8.31 & $\mathrm{~J} \mathrm{~K}^{-1} \mathrm{~mol}^{-1}$ & Van Cappellen et al. (2002) \\
\hline
\end{tabular}

State variable

Equation

Dia

$\frac{\partial \operatorname{Dia}}{\partial t}=\operatorname{Dia} \times\left[\mu_{\text {maxDia }} \times f(T) \times \min \left(f(l)_{\text {Dia }}, f(N)_{\text {Dia }}, f(S i)_{\text {Dia }}\right)-\eta_{\text {Dia }} \times f(T)\right]-\operatorname{sed}_{\text {Dia }}-C_{\text {Zoo }}^{\text {Dia }}-C_{\text {Ben }}^{\text {Dia }}$

with $f(\mathrm{~N})=\exp ^{(0.07 \times T)}$ for the temperature function

$$
\begin{aligned}
& f(N)_{\text {Dia }}=\frac{D I N}{D I N+k N_{\text {Dia }}} \text { for diatom growth limitation by DIN availability } \\
& \operatorname{sed}_{\text {Dia }}=\operatorname{Dia} \times \frac{1}{H} \times v_{\text {sed }} \times \min \left(1, \frac{H}{l}\right) \text { for the sedimentation of diatoms where } H \text { is water depth }
\end{aligned}
$$

and $f(I)_{\text {Dia }}=\frac{1}{H} \times \int_{0}^{H} \frac{I_{z} \cdot P_{\text {act }}}{I_{\text {optDia }}} \times \exp \left(1-\frac{I_{z} \cdot P_{\text {act }}}{I_{\text {optDia }}}\right) \mathrm{d} z \quad$ for the light limitation function for diatoms

using $I_{z}=I_{\text {surf }} \times \exp ^{(-K \times z)}$ and $K=K_{\mathrm{nc}}+0.04 \times(\text { Dia }+ \text { Dino })^{0.6}$

Dino $\quad \frac{\partial \text { Dino }}{\partial t}=$ Dino $\times\left[\mu_{\text {max Dino }} \times f(T) \times \min \left(f(l)_{\text {Dino }} f(N)_{\text {Dino }}\right)-\eta_{\text {Dino }} \times f(T)\right]-C_{\text {Zoo }}^{\text {Dino }}-C_{\text {Ben }}^{\text {Dino }}$

Zoo $\quad \frac{\partial Z o o}{\partial t}=Z o o \times\left[\mu_{\mathrm{Zoo}} \cdot f(T)-\eta_{\mathrm{Zoo}} \cdot f(T)-\rho_{\mathrm{Zoo}} \cdot f(T)\right]$

with $\mu_{\mathrm{Zoo}}=\left(1-\varepsilon_{\mathrm{Zoo}}\right)\left(G_{\mathrm{Zoo}}^{\mathrm{Dia}}+G_{\mathrm{Zoo}}^{\text {Dino }}\right)$ where $G_{\mathrm{Zoo}}^{\mathrm{Dia}}=\mu_{\max }^{\text {Dia }} \frac{I_{\text {Dia }}}{K_{\mathrm{Zoo}}+F}$ and $G_{\mathrm{Zoo}}^{\text {Dino }}=\mu_{\max }^{\text {Dino }} \frac{I_{\text {Dino }}}{K_{\mathrm{Zoo}}+F}$

$$
F=\operatorname{Dia} \cdot \rho_{\text {Dia }}+\text { Dino } \cdot \rho_{\text {Dino }}
$$$$
I_{\text {Dia }}=\frac{\text { Dia } \cdot p_{\text {Dia }}}{\operatorname{Dia} \cdot p_{\text {Dia }}+\text { Dino } \cdot p_{\text {Dino }}} \text { and } \quad I_{\text {Dino }}=\frac{\text { Dino } \cdot p_{\text {Dino }}}{\operatorname{Dia} \cdot p_{\text {Dia }}+\operatorname{Dino} \cdot p_{\text {Dino }}}
$$

and $\eta_{\mathrm{Zoo}}=\max \left(m_{0}, m_{\mathrm{dd}}\right) \cdot \mathrm{Zoo}$

Thus $C_{\mathrm{Zoo}}^{\text {Dia }}=Z o o \times f(T) \times G_{\mathrm{Zoo}}^{\text {Dia }} \quad$ and $\quad C_{\mathrm{Zoo}}^{\text {Dino }}=Z o o \times f(T) \times G_{\mathrm{Zoo}}^{\text {Dino }}$

DIN

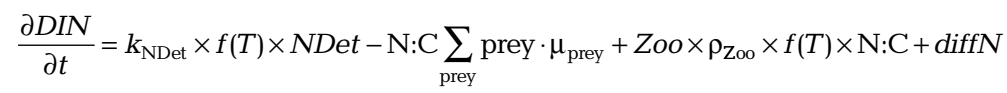

with $\operatorname{diffN}=-k_{\mathrm{difN}} \times \frac{\frac{B D I N}{l}-D I N}{l}$

NDet

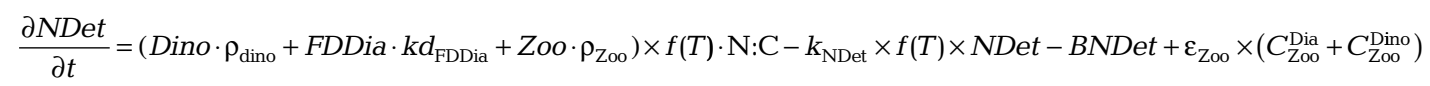


Appendix 1 (continued)

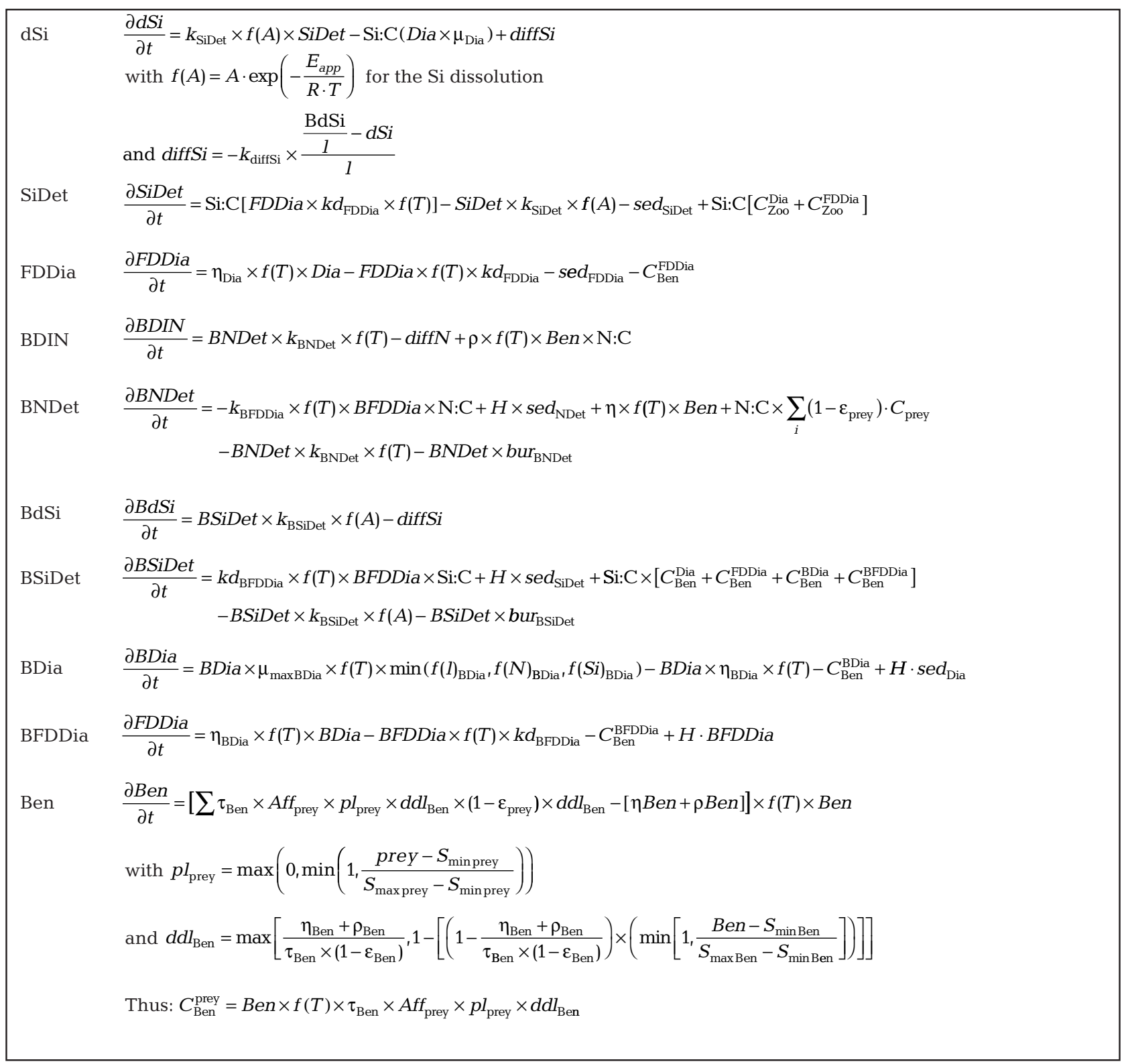

Editorial responsibility: Alain Vézina, Dartmouth, Nova Scotia, Canada
Submitted: June 23, 2008; Accepted: December 10, 2008 Proofs received from author(s): May 25, 2009 